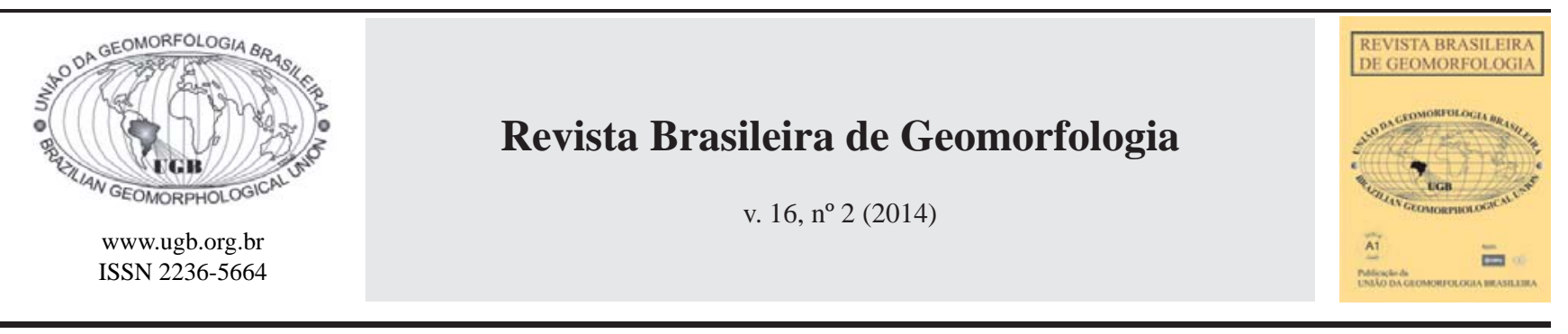

\title{
COMPARAÇÃO DA DINÂMICA EVOLUTIVA, EM LONGO E CURTO PRAZO, ENTRE O PLANALTO DE POÇOS DE CALDAS E O PLANALTO DE SÃO PEDRO DE CALDAS
}

\author{
COMPARISON OF LONG AND SHORT TERM EVOLUTIONARY \\ DYNAMICS, BETWEEN THE POÇOS DE CALDAS PLATEAU AND THE \\ SÃO PEDRO DE CALDAS PLATEAU
}

Daniel Henrique de Souza

Instituto de Geociências e Ciências Exatas de Rio Claro, Universidade Estadual Paulista. Av. 24A, 1515 - Bela Vista, Rio Claro/SP - Cep: 13506-900, Brasil.

E-mail:danieudani@yahoo.com.br

Peter Christian Hackspacher Instituto de Geociências e Ciências Exatas de Rio Claro, Universidade Estadual Paulista. Av. 24A, 1515 - Bela Vista, Rio Claro/SP - Cep: 13506-900, Brasil.

E-mail:phack@rc.unesp.br

Carolina Doranti-Tiritan

Instituto de Geociências e Ciências Exatas de Rio Claro, Universidade Estadual Paulista. Av. 24A, 1515 - Bela Vista, Rio Claro/SP - Cep: 13506-900, Brasil. E-mail: cadoranti@gmail.com

Daniel Françoso de Godoy

Instituto de Geociências e Ciências Exatas de Rio Claro, Universidade Estadual Paulista. Av. 24A, 1515 - Bela Vista, Rio Claro/SP - Cep: 13506-900, Brasil.

E-mail:dfgodoy@gmail.com

Informações sobre o Artigo

Data de Recebimento:

09/12/2013

Data de Aprovação:

$26 / 05 / 2014$

\section{Palavras-chave:}

Traço de fissão em apatitas; análise morfométrica; rede de drenagem; blocos topográficos.

\section{Keywords:}

Apatite fission track, morphometric analysis, drainage network, topographic blocks.

\section{Resumo:}

Este trabalho utiliza metodologias que permitem o estudo de evolução da paisagem a longo-prazo (termocronologia por traço de fissão em apatita - TFA) e curto-prazo (análise morfométrica da rede de drenagem, pelo índice de relação declividade - extensão dos canais de drenagem - RDE) para compreender a dinâmica de evolução de dois planaltos vizinhos no sul de Minas Gerais - Brasil: o planalto de Poços de Caldas e o Planalto de São Pedro de Caldas. Os resultados apresentam ritmos de soerguimentos diferenciados para ambos os planaltos, identificados pela diferença na relação entre topografia e idade de TFA. No primeiro, formado por processos de intrusão magmática e vulcanismo no Cretáceo Superior, há uma relação inversa entre idade e altitude, com as idades mais recentes nas regiões elevadas; no segundo, originado por soerguimento epirogênico, ocorre o contrário, as idades decrescem com a diminuição da altitude. Em ambos os casos, atividades tectônicas ocorridas ao longo do Cenozóico desnivelaram e compartimentaram 
os blocos topográficos. Os limites destes blocos, geralmente coincidentes com contatos litológicos e lineamentos morfoestruturais, são também marcados por valores altos de RDE, indicando atuação erosiva recente nestas áreas, em oposição aos valores baixos, no interior dos planaltos, sugerindo a estabilidade destas áreas. Verificamos assim a preservação de antigas superfícies erosivas e a importância dos eventos tectônicos e magmáticos pretéritos na compartimentação atual do relevo, em escala regional.

\begin{abstract}
:
This work uses methodologies that allow the study of landscape evolution in the long-term (thermochronology by apatite fission track - AFT) and short-term (morphometric analysis of the drainage network, by the slope - length index of drainage channels - SL) to understand the dynamics of evolution of two neighboring plateaus in the south of Minas Gerais - Brazil: the Poços de Caldas plateau and the São Pedro de Caldas plateau. The results show different rates of uplift for both plateaus, identified by the difference in the relationship between topography and AFT ages: in the first one, formed by processes of magmatic intrusion and volcanism in the Upper Cretaceous, there is an inverse relationship between age and height, the most recent ages in higher regions; in the second, originated by epeirogenic uplift, the opposite occurs, the ages decrease as altitude decreases. In both cases, tectonic activities occurred throughout the Cenozoic provoked uneveness and partitioning of the topographic blocks. The boundaries of these blocks, generally coincident with lithologic contacts and morphostructural lineaments, are also marked by high values of SL, indicating recent erosive action in these areas, as opposed to low values within the plains, suggesting the stability of these areas. We then verified preserving old erosional surfaces and the importance of past tectonic and magmatic events in the current relief partitioning on a regional scale.
\end{abstract}

\section{1 - Introdução}

A forma apresentada pelo relevo está intimamente ligada a processos de soerguimento, exumação, erosão, compactação e subsidência. Assim sendo, a quantificação de taxas destes processos ao longo do tempo torna se de fundamental importância para o entendimento do modo como se deu a evolução do relevo (REINERS \& BRANDON, 2006; BISHOP, 2007). Estas taxas se relacionam diretamente com a história de resfriamento de uma rocha através da crosta, o qual resulta de processos de exumação a partir de soerguimento tectônico das rochas ou/e erosão continua em superfície. Esta história pode ser quantificada por termocronômetros de baixa temperatura (e.g.: traço de fissão e (U/Th)-He em apatita ou zircão), os quais registram as taxas de resfriamento de um mineral a partir de diferentes temperaturas de fechamento, à medida que é exumado através da crosta rasa (BRAUN, 2002; REINERS \& BRANDON, 2006).

A partir destes termocronômetros, gráficos de relação entre idade e elevação topográfica são utilizados para estimar taxas de exumação e erosão e os processos atuantes (FRANCO-MAGALHÃES, 2009). Os processos desenvolvidos pela denudação tectônica e erosional apresentam reflexos na disposição da temperatura da crosta superior, o que pode ser notado na variação vertical e horizontal das isotermas (TURCOTTE \& SCHUBERT, 1982). Estas se definem como faixas de temperaturas dispostas em profundidade na crosta controladas pelos processos de condução de calor, e, a propósito de estudos podem ser correlacionadas às temperaturas de fechamento dos termocrômetros. Estas faixas são perturbadas pela amplitude topográfica do relevo (que resultam dos processos de denudação acima citados), tendendo a acompanhar grosseiramente o seu traçado. A perturbação decresce exponencialmente com a profundidade, e proporcionalmente a amplitude topográfica, de modo que, relevos de baixa amplitude, em profundidades maiores, não afetam substancialmente a forma da isoterma (TURCOTTE \& SCHUBERT, 1982; STUWE et al., 1994; MACKTELOW \& GRASEMANN, 1997; STUWE \& HINTERMULLER, 2000; BRAUN, 2002). Sob condições termais da crosta em estado estacionário (steady-state), rochas datadas pelos termocronômetros de baixa temperatura devem aumentar linearmente a idade com a elevação, isto porque as amostras exumadas em áreas topograficamente elevadas teriam passado pela isoterma anteriormente às encontradas em áreas baixas. Esta diferença de idade é maior em temperaturas de fechamento mais elevadas, já que nestas a perturbação do relevo na isoterma é menor. Nestes termos, idades antigas no topo, e idades jovens 
em altitudes baixas configurariam denudação erosional. Por outro lado, uma inversão nesta tendência poderia indicar controle tectônico de erosão (BRAUN, 2002).

Entretanto, estes termocronômetros não são capazes de detectar algumas flutuações que ocorrem a curto-prazo nas taxas de erosão e soerguimento da topografia, isto porque suas medições registram apenas uma média destas taxas a longos períodos de tempo, na escala de milhões de anos (FELLIN et al., 2005). Segundo alguns autores (PAZZAGLIA et al., 1998; FELLIN et al., 2005), tais flutuações podem ser inferidas, através dos terraços de canais bedrock e pelas formas apresentadas pelos perfis longitudinais dos canais de drenagem, que podem prover taxas de incisão do rio, a variação espacial do soerguimento das rochas e indicar a estabilidade da rede de drenagem, nos últimos milhares de anos. Assim, Fellin et al. (2005), Pazzaglia e Brandon (2001), sustentam que padrões semelhantes entre taxas de incisão pelas redes de drenagens e taxas de erosão registrados nos termocronometros de baixa temperatura podem indicar relevo em estado estácionário (steady state). Caso contrario, detecta-se uma flutuação atual na média obtida em longos períodos de tempos. Além disso, sendo a rede de drenagem sensível às mudanças ambientais, e com tendência de adaptação as estruturas pré-existentes, controles ativos e passivos operam juntos influenciando o desenvolvimento dos sistemas de drenagens (SUMMERFIELD, 1991), de modo que, um sistema estabelecido apresenta em sua configuração elementos que reflitam eventos pretéritos e presentes.

Entende-se desta maneira, que a utilização em conjunto entre análise de perfil longitudinal de drenagens e termocronologia de baixa temperatura, correlacionando taxas de soerguimento a curto e a longo prazo, podem possuir relação de complementariedade e, seriam, desta maneira, eficaz ao entendimento da dinâmica de soerguimento de uma região. Para testar esta possibilidade, este trabalho pretende investigar a dinâmica evolutiva do Planalto Sul de Minas, no sudeste brasileiro, através do uso em conjunto de termocronologia de baixa temperatura por traço de fissão em apatitas (TFA) e análise morfométrica da drenagem, pelo índice de relação declividade - extensão dos canais de drenagens (RDE).

Este planalto, constituído por rochas cristalinas do Pré-Cambriano e Cambro-Ordoviciano do segmento central da Província Mantiqueira, tem como particularidade uma intrusão alcalina do final do período Cretáceo que corta o embasamento cristalino, o qual deu origem ao Planalto Poços de Caldas, uma estrutura anelar constituída por relevo acidentado repleto de vertentes abruptas. À leste desse planalto, no embasamento précambriano, encontra-se outra região elevada, com altitudes semelhantes denominada Planalto de São Pedro de Caldas (Figura 1). Aplicar e correlacionar os métodos empregados a fim de compreender a dinâmica evolutiva e identificar as diferenças nas taxas de soerguimento e erosão destes dois planaltos consiste é o objetivo deste trabalho.

\section{2 - Contexto Geológico e geomorfológico:}

Aárea de estudos insere-se no contexto da Província Mantiqueira, um sistema orogênico paralelo a costa atlântica do sudeste e sul do Brasil (ALMEIDA et al., 2000), formada no ciclo Brasiliano. O setor central da província, região de interesse deste trabalho, é constituído pelos Orógeno Brasília Meridional, Orógeno Ribeira, e a Zona de Interferência entre ambos e os terrenos Apiaí, São Roque e Embu, originados numa sequência de colisões que vão de 630 a 510 Ma (HEILBRON et al. 2004). Suas rochas, constituintes de fragmentos crustais de diferentes idades e níveis metamórficos, representando os diferentes estágios da tectônica de placas pelo qual passou a evolução da província (Figura 2).

A região de estudo passou por sucessivos estágios de evolução. Após diminuição dos processos de dobramentos, a plataforma passou gradualmentente para uma fase de estabilização (ALMEIDA el al., 2000) caracterizada por calmaria tectônica e a formação de grandes sinécleses, tais como a Bacia do Paraná, atualmente adjacente a área de estudos. Esta bacia tem seus principais pulsos de subsidência e sedimentação controlados por fases de orogenia ocorridas na margem sul-ocidental do Gondwana (MILANI, 2004). Evidencias da bacia do Paraná ter coberto a região é indicada por Ellert (1959) e Björnberg (1959), que descreveram rochas sedimentares no interior e nas rochas que bordejam o Maciço Alcalino de Poços de Caldas, correlacionadas à Formação Botucatu por Ulbrich e Ulbrich (1992). Também, Oliveira et al. (1975), descreveram sedimentos da formação Botucatu soterrados por conglomerados associados às 


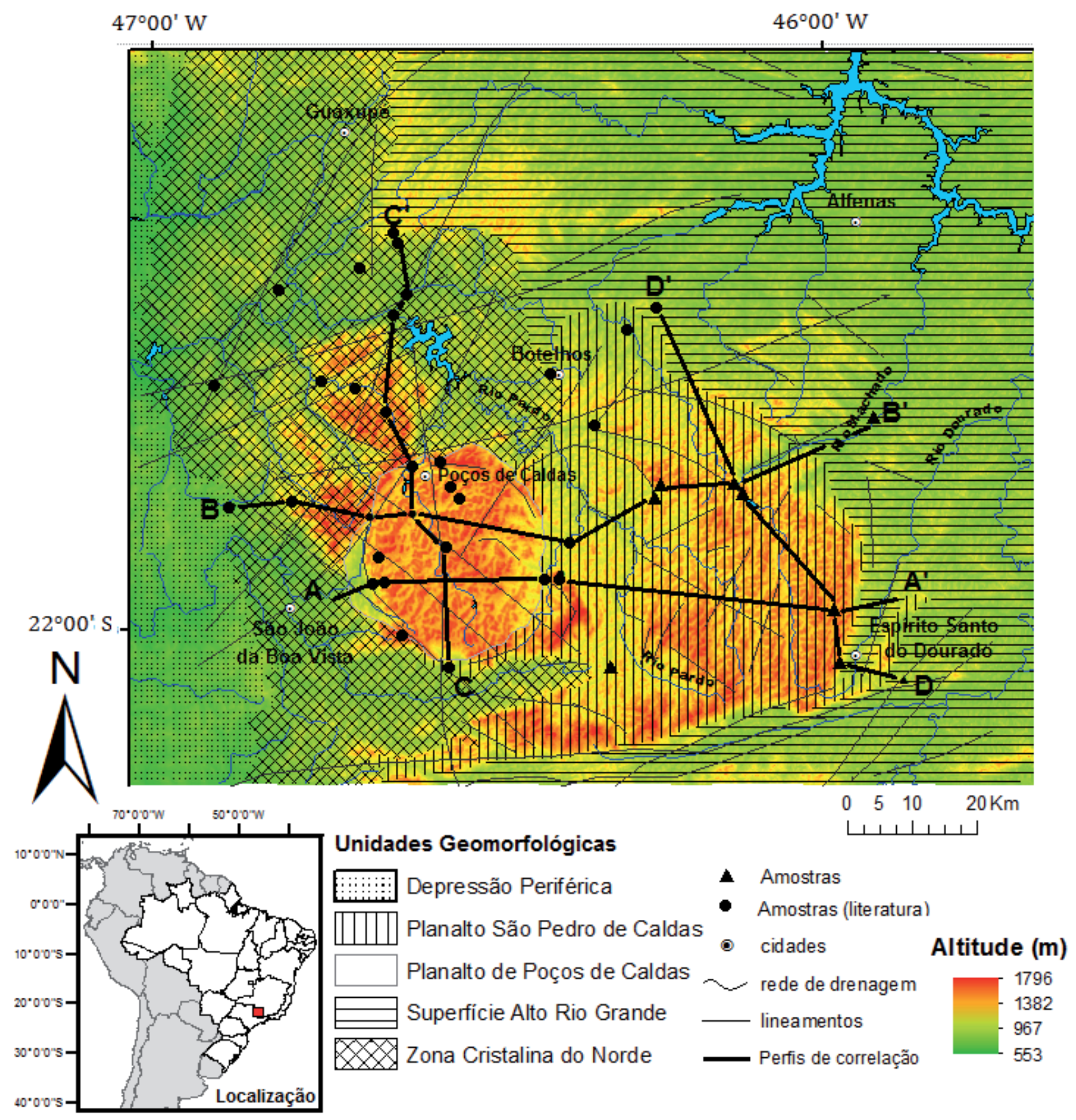

Figura 1 - Área de estudos: localização e unidades geomorfológicas

rochas vulcânicas alcalinas, em Divinópolis, as 12 Km de Poços de Caldas.

Reativações tectônicas ocorreram na Plataforma Brasileira a partir do no Neo-Jurássico (reativação Wealdeniana - ALMEIDA, 1969), relacionadas à fragmentação do Gondwana e abertura do oceano Atlântico, através de evento distenscional precedido de magmatismo basáltico toleítico. Tal magmatismo, no interior do continente da origem aos basaltos da formação Serra
Geral, na Bacia do Paraná. (MILANI, 2004).

Devido ao peso do material formado pela atividade vulcânica e conseqüente compactação das camadas sedimentares, teria ocorrido um contínuo processo de subsidência da Bacia do Paraná (MILANI, 1997) - e a sedimentação do Grupo Bauru. Em contra partida, ocorre o que Tello Saenz et al., (2003), e Hackspacher et al. (2004, 2007), sustentados por idades de TFA em torno de 127 Ma, denominam de formação inicial da Serra 


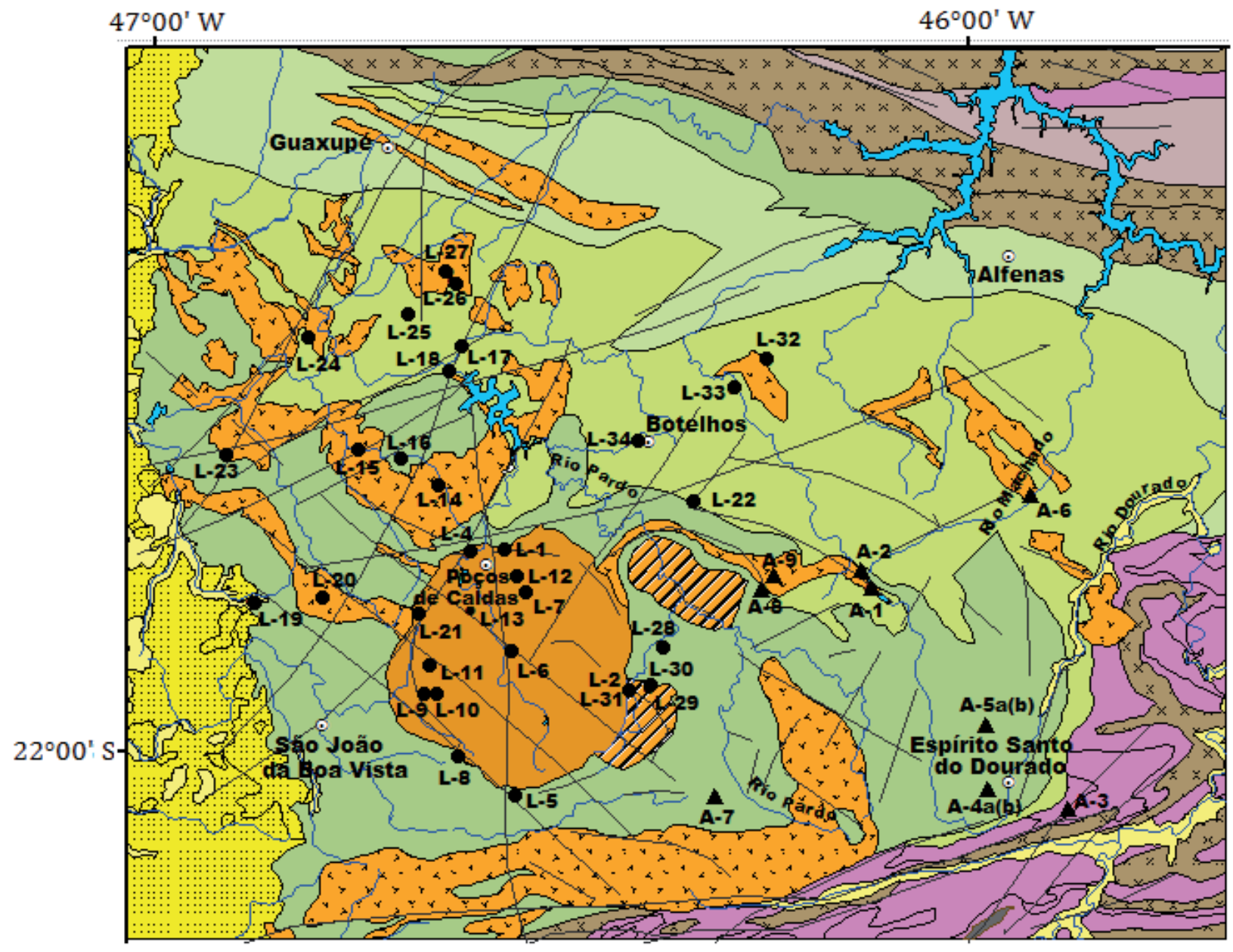

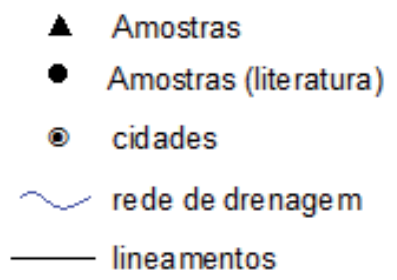

Fanerozóico

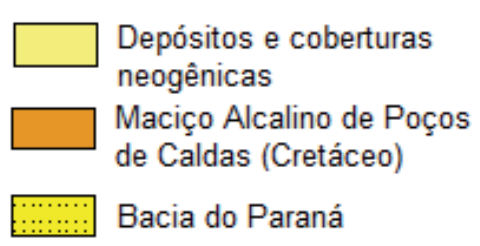

\section{Neoproterozóico}

Complexo Socorro Guaxupé

(Arco Magmático/ Orogeno)

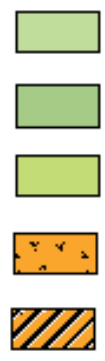
Unidade Granulitica Basal
Unidade Ortognaissica
Migmatítica Intermediária
Unidade Paragnaissica
Migmatítica Superior

Intrusões Sin-Orogenicas

(granitos, mangeritos, charnoquitos)

Intrusões Pós-Orogenicas

(Sienitos)

Supracrustais do Cinturão Brasilia (Grupos Araxá, Canastra, Andrelandia e Carrancas)

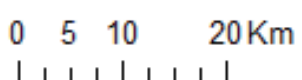

Paleoproterozóico

Complexo Amparo

\section{Arqueano}

Complexo Lavras (greenstone belts)

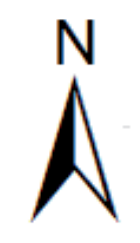

Figura 2 - Geologia e localização das amostras.

da Mantiqueira, causado pelo soerguimento marginal de flancos de rift iniciado durante a abertura oceânica. Estes fatos, de acordo com Mello et al. (1993), impõem, na região do Rio Pardo, área de abrangência deste estudo, um padrão normal de drenagem conseqüente com direção NW, partindo da área soerguida para a bacia do Paraná.

Cessado o rifteamento, a 98 Ma se inicia a fase de deriva continental. Um soerguimento epirogenético generalizado no embasamento pré-cambriano da região 
sudeste é registrado entre 85 - 65 Ma (TELLO SAENZ et al., 2003) em reposta a possível passagem da Placa Sul - Americana de leste para oeste sobre uma anomalia térmica (ZALÁN E OLIVEIRA, 2005, THOMAZ- FILHO et al. 2005), gerando uma seqüência de intrusões alcalinas denominada de Alinhamento de Rochas Alcalinas Poços de Caldas - Cabo Frio (FREITAS, 1947, ALMEIDA et al. 1996), que segue a direção WNW-ESSE se estendendo do estado de Minas Gerais até o Rio de Janeiro, com idades decrescentes, variando do Cretáceo Superior ao Eoceno (THOMAZ-FILHO et al. 2005). Tal soerguimento gerou um megaplanalto no sudeste brasileiro denominado por Zalán e Oliveira (2005) de Serra do Mar Cretácea. Este, a partir de então, sofreu um processo erosivo generalizado que iria aplainar e nivelar toda a região, dando origem a Superfície de Aplainamento Japi, ou Sul-Americana (KING, 1956).

Um novo pulso ascensional terminaria por delinear as configurações gerais do relevo atual. Foi responsável pela formação do Sistema de Riftes Cenozóicos do Sudeste do Brasil. Dados de traço de fissão em apatitas data o evento como pós-60 Ma (TELLO SAENZ et al. 2003), com clímax no Eoceno-Oligoceno (HACKSPACHER et al. 2003). Segundo Zalán e Oliveira (2005) este pulso teria natureza não ascencional, e sim de colapso. O megaplanalto soerguido e aplainado pela superfície Japi (Sul Americana) apresentaria situação gravitacional instável, de maneira que começou a rachar e colapsar. Este processo gerou relevo vertical por abatimento seletivo de blocos, criando grábens e ombreiras e rejuvenescendo a erosão do embasamento cristalino.

O Sistema de Riftes Cenozóicos do Sudeste do Brasil possui maior expressividade na associação entre serras do Mar/Mantiqueira com os vales tectônicos intervenientes, possuindo porém, de acordo com Zalán e Oliveira (2005), extensões na plataforma continental das bacias de Santos/Campos. Segundo Melo et al (1993), o sistema possui também prolongamento no interior do continente, com feições que decaem em magnitude conforme se distanciam da borda continental, o qual, poderia ter sua expressão na área de estudo, no sistema de falhas Rio Pardo, representado pelos lineamentos de direção ENE-WSW (ALMEIDA FILHO E PARADELLA, 1977; OLIVEIRA et al, 1989; MELLO et al,1993).

Quanto a classificação geomorfológica, a área insere-se, dentro do Planalto Atlântico, nos setores denominados de Planalto Sul de Minas e Zona Cris- talina do Norte (ALMEIDA, 1964, CAVALCANTI et. al.,1979, PONÇANO, 1981, ROSS, 1992). O Planalto Sul de Minas, por sua vez, subdivide-se em três setores: Planalto Poços de Caldas, Superfície do Alto Rio Grande e Planalto São Pedro de Caldas (Figura 1).

O Planalto de Poços de Caldas possuí cerca de $800 \mathrm{~km}^{2}$, destacando-se cerca de 300 a $500 \mathrm{~m}$ do entorno cristalino. Este planalto encontra-se estabelecido numa chaminé de rochas eruptivas alcalinas (ALMEIDA, 1964), representada principalmente por foiaítos e tinguaítos (CAVALCANTI, et. al., 1979). Ele possui estrutura anelar circundando uma zona rebaixada onde se desenvolve uma topografia de morros e vertentes suaves (CAVALCANTI, et. al., 1979). Com importância destacada no relevo regional, sua história inicia-se com a intrusão de rochas félsicas em aproximadamente $89 \mathrm{Ma}$, acarretando em domeamento da região, e estende-se até cerca de 54 MA(SONOKI \& GARDA 1988, ULBRICH et al., 2002), através de episódios de vulcanismo, abatimento do conduto vulcânico e estruturação da caldeira (ELLERT, 1959).

O Planalto de São Pedro de Caldas, a leste de Poços de Caldas, atingindo atitudes similares a este no topo, é formado por extensas formas de topos convexos com diferença altimétrica para com os fundos de vale, em torno de 80 a 90m. O Planalto de São Pedro possui também escarpas adaptadas as falhas ou escarpas de falhas, caracterizadas por feições tipo facetas trapezoidais nas bases. Algumas destas escarpas apresentam fissuras aparentando o deslocamento de blocos com elevação e/ ou abatimento. A Superfície Alto Rio Grande, por sua vez, consiste essencialmente numa extensa superfície caracterizada por relevo ondulado, possuindo altitudes situadas em volta de $900 \mathrm{~m}$ onde se destacam cristas que atingem altitudes acima de $1000 \mathrm{~m}$.

A Zona Cristalina do Norte consiste na área de transição entre as terras altas do sudoeste de Minas Gerais e a região sedimentar da Depressão Periférica. Ela possui estrutura complexa (ALMEIDA, 1964, CAVALCANTI et al., 1979), no qual a oeste, na vizinhança da orla sedimentar, seu relevo montanhoso tem seus cimos condicionados pela superfície "Itaguá", pré-permiana, alcançando $1200 \mathrm{~m}$ de altitude, os quais são ultrapassados a leste, onde sofre influência da superfície “Japi”, chegando a $1600 \mathrm{~m}$, sendo deformada por falhas e flexuras (ALMEIDA, 1964), que podem ser observadas nas regiões que abrangem as cidades de São Sebastião da Grama, Vargem Grande do Sul e 
Divinolândia, onde perturbações tectônicas elevam a superfície a cerca de $1550 \mathrm{~m}$, tanto na área gnáissica quanto nas áreas alcalinas de Poços de Caldas. De acordo com Almeida (1964), os falhamentos atuaram mesmo após a sedimentação do Grupo Bauru, elevando à altitude de 1550 m o testemunho cretáceo da Serra do Mirante, além de sedimentos localizados em Águas da Prata.

\section{3 - Materiais e métodos}

\section{1 - Termocronologia por Traços de Fissão em Apatitas}

O método consiste na análise, ao microscópio óptico de traços gerados pela fissão espontânea do $\mathrm{U}^{238}$, os quais são registrados ao longo do tempo geológico no mineral. (WAGNER \& VAN DEN HOUTE 1992). Estes traços possuem graus de estabilidade de acordo com a temperatura ao qual o detector é exposto, no caso do mineral de apatita, eles são formados e apagados lentamente a temperaturas entre $60^{\circ} \mathrm{C}$ e $120^{\circ} \mathrm{C}$, faixa esta, equivalente a aproximadamente $4 \mathrm{Km}$ de profundidade de crosta (considerando o gradiente geotérmico regular de $30^{\circ} \mathrm{C} / \mathrm{Km}$ - HAMZA et al., 1989), conhecida como Zona de Annealing Parcial. Acima de $120^{\circ} \mathrm{C}$, os traços são totalmente apagados, devido a reorganização estrutural do mineral, essa faixa é chamada de Zona de Annealing Total. Por outro lado, abaixo de $60^{\circ}$, os traços são preservados, é a Zona de Estabilidade Total. Assim, as datações obtidas pela análise de traços de fissão indicam a última vez que o mineral passou pela Zona de Annealing Parcial. A análise desta constatação pode indicar diversos significados geológicos e geomorofológicos, como eventos tectônicos, taxas de soerguimentos, inferências na denudação e exumação local, subsidência, etc.

Para a análise, nas dependências do Departamento de Mineralogia e Petrografia (DPM), e laboratórios Núcleo de Cronologia e Cronometria, Unesp - Rio Claro, as amostras coletadas em campo passaram por etapas de britagem, peneiramento, bateamento, separação magnética (separador magnético Frantz), separação química por líquidos pesados (bromofórmio) e separação manual dos cristais de apatita em lupa com aumento de 40x. Os grãos separados foram montados em resina do tipo epóxi, a qual foi polida e atacada quimicamente em solução de $\mathrm{HNO}_{3}$, visando a revelação dos traços fósseis (aumento da espessura do traço, tornando-o visível no microscópio).
Para calcular as idades, foi utilizado o método do detector externo, onde a amostra é irradiada (reator nuclear de pesquisa FRM II, em Munique) com uma lamínula de moscovita acoplada, a qual registrará os traços da fissão induzida (fissão do ${ }^{235} \mathrm{U}$, que possui razão isotópica constante na natureza com o ${ }^{238} \mathrm{U}$, permitindo a utilização de alguns fatores de difícil determinação nos traços fósseis). Este método permite medir em microscópio óptico com aumento de 1000x a densidade de traços fósseis $\left({ }^{238} \mathrm{U}\right)$ e induzidos $\left({ }^{235} \mathrm{U}\right)$ em cada grão, de modo que é possível calcular a idade para cada grão analisado.

Após irradiada, a mica é atacada quimicamente e solução de HF para revelação dos traços induzidos. Após isso, a densidade de traços é contada através do microscópio. Para o cálculo das idades de traços de fissão em apatitas foi utilizado o método de calibração Zeta, que se baseia no cálculo de um fator de correção através de uma amostra padrão, no caso, a apatita Durango (HURFORD \& GREEN, 1983). Das onze amostras utilizadas, três amostras já estavam previamente irradiadas no reator nuclear de pesquisa do IPEN/ CNEN em São Paulo, sendo que a calibração destas foi realizada a partir de fator Zeta calculado de uma amostra padrão irradiada neste mesmo reator.

\section{2 - Relação Declividade vs. Extensão de curso d'água (RDE)}

A relação declividade - extensão de canal (RDE) é um índice, sem unidade de medida, formulado por Hack (1973) que se refere à declividade de um determinado trecho de um canal de drenagem normalizado pela distancia do referido trecho à cabeceira. Esta diretamente relacionado com os níveis de energia da corrente (stream power ) (KELLER E PINTER, 1996).

O índice possibilita a comparação entre diferentes canais e segmento de canais, permitindo a análise do comportamento da drenagem sob distintos substratos rochosos, e diferentes condições tectônicas e climáticas. Seu cálculo se realiza pela seguinte equação:

$$
\mathrm{RDE}=(\mathrm{Dh} / \mathrm{Dl}) . \mathrm{L}
$$

Onde Dh é diferença altimétrica entre dois pontos extremos de um segmento ao longo do curso d'água; Dl a projeção horizontal da extensão do referido segmento; 


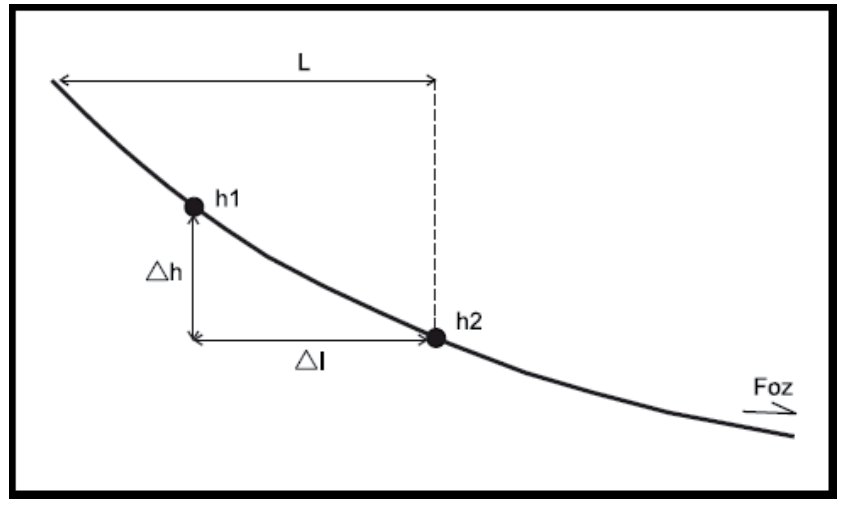

Figura 3 - Parâmetros utilizados no índice RDE. (Fonte: Etchebehere et al., 2004)

e L - comprimento total do curso d'água a montante do ponto para o qual o índice RDE estásendo calculado. Estas variáveis poder ser visualizadas na figura 3.

Neste trabalho, os trechos referem-se a segmentos de determinada ordem de hierarquia fluvial (STRAHLER, 1952). Esta opção se deu ao levar em consideração que uma determinada ordem de drenagem numa hierarquia fluvial pode referir-se a eventos e idades geológicas semelhantes (GOLTS E ROSENTHAL, 1993; HODGKINSON et al. , 2006), de modo que, uma superfície de nível de base relacionada a uma determinada ordem pode ser considerado como produto de um evento tectônico-magmático-erosional (GROHMANN et al., 2011).
A partir de imagens SRTM, foi extraída e hierarquizada a rede de drenagem, através das ferramentas do grupo Hidrology, da ArcToolBox Spatial Analyst Tools, dentro do programa ArcGis 10. As variáveis da equação foram mensuradas a partir das ferramentas Calculate Geometry e Zonal Statistics as Table. As variáveis foram tabuladas em planilhas do programa Microsoft Excel, onde foram realizados os cálculos da equação e as estatísticas descritivas dos resultados. O mapa de isovalores foi confeccionado utilizando-se o programa Surfer 8, onde os resultados foram interpolados pelo método de Vizinhos Naturais.

\section{4 - Resultados e discussões}

\section{1 - Análise de Traço de fissão em apatitas (ATFA)}

As tabelas 1 e 2 apresentam os as idades obtidas neste trabalho, as quais foram inseridas no contexto de outras 34 amostras retiradas da literatura - Godoy (2003), Franco et al. (2005), Doranti (2006), Silva (2010) e Doranti-Tiritan (2013), completando a área de estudo (tabela 3). A localização geográfica das amostras pode ser visualizada na figura 2 .

Para análise dos resultados, foram confeccionados um mapa de isovalores de idades de traço de fissão em apatitas, através do método de interpolação de mínima curvatura (figura 4) e uma gráfico de relação idade e altitude (gráfico 1). A análise em conjunta destes produtos

Tabela 1 - Parâmetros físicos e idade das amostras (reator: FRM II - Munique): total de grãos (N), somatória de traços fosseis contados (Ns) somatória de traços induzidos contados (Ni), densidade de traços fósseis $(\mathrm{RhoS})(.10 \wedge 5$ traços/ $\mathrm{cm} 2)$, densidade de traços induzidos (RhoI) $(.10 \wedge 5$ traços/ $\mathrm{cm} 2)$ e Probabilidade de qui quadrado P(Chi-sq. P). As idades de TFA foram calculadas utilizando o fator Zeta de $305.68 \pm 14.05$ para o dosímetro CN5

\begin{tabular}{|cccccccc|c|}
\hline Amostra & Rocha & $\mathrm{N}$ & $\mathrm{Ns}$ & $\mathrm{Ni}$ & $\mathrm{RhoS}$ & RhoI & $\begin{array}{c}\text { Chi-sq. } \\
\mathrm{P}(\%)\end{array}$ & Idade central \\
\hline A-1 & Granito & 55 & {$[2243]$} & {$[2808]$} & 36.392 & 45.559 & 0.17 & $167.7 \pm 10.1$ \\
A-2 & Granito & 47 & {$[1275]$} & {$[2168]$} & 33.656 & 57.229 & 43.3 & $125.3 \pm 7.5$ \\
A-3 & Gnaisse & 41 & {$[663]$} & {$[1247]$} & 15.057 & 28.32 & 91.65 & $113.4 \pm 7.7$ \\
A-4a & Gnaisse & 63 & {$[1366]$} & {$[1201]$} & 17.502 & 15.388 & 89.26 & $240.2 \pm 15$ \\
A-4b & Biotitagnaisse & 87 & {$[1006]$} & {$[965]$} & 15.291 & 14.667 & 99.99 & $220 \pm 14.5$ \\
A-5a & Gnaisse & 49 & {$[1129]$} & {$[1166]$} & 44.547 & 46.007 & 76.68 & $204.6 \pm 13.1$ \\
A-5b & Gnaisse/Xisto & 65 & {$[1712]$} & {$[1708]$} & 45.493 & 45.387 & 94.38 & $211 \pm 12.5$ \\
A-6 & Granito & 57 & {$[1054]$} & {$[1389]$} & 28.592 & 37.679 & 2.19 & $161.7 \pm 11.3$ \\
\hline
\end{tabular}


Tabela 2 - Parâmetros físicos e idade das amostras (reator: IPEN/ CNEN - São Paulo) : total de grãos (N), somatória de traços fosseis contados (Ns) somatória de traços induzidos contados (Ni), densidade de traços fósseis (RhoS) (.10^5 traços/ cm2), densidade de traços induzidos (RhoI) $(.10 \wedge 5$ traços/ $\mathrm{cm} 2)$ e Probabilidade de qui quadrado $\mathrm{P}(\mathrm{Chi}$-sq. $\mathrm{P})$. Fator Zeta: $337 \pm 25.92$ para o dosímetro CN5

\begin{tabular}{|cccccccc|c|}
\hline Amostra & Rocha & $\mathrm{N}$ & {$[\mathrm{Ns}]$} & {$[\mathrm{Ni}]$} & RhoS & Rhol & $\begin{array}{c}\text { Chi-sq. P } \\
(\%)\end{array}$ & Idade central \\
\hline A-7 & Ortognaisse & 73 & {$[1094]$} & {$[1133]$} & 12.683 & 13.135 & 99,76 & $70,2 \pm 6,2$ \\
A-8 & Ortognaisse & 49 & {$[1060]$} & {$[504]$} & 3.183 .183 & 1.513 .514 & 0,03 & $148,4 \pm 16,2$ \\
A-9 & Granulito & 34 & {$[559]$} & {$[266]$} & 27.079 & 12.886 & 67,97 & $153,1 \pm 16,7$ \\
\hline
\end{tabular}

Tabela 3 - Amostras retiradas da literatura

\begin{tabular}{|c|c|c|c|c|}
\hline Amostra & $\begin{array}{l}\text { Nome } \\
\text { original }\end{array}$ & $\begin{array}{l}\text { Idade Central } \\
\text { (Ma) }\end{array}$ & Rocha & Autor \\
\hline L-1 & $\mathrm{TF}-311$ & $60 \pm 6$ & fonólito & Godoy (2003) \\
\hline L-2 & $\mathrm{TF}-313$ & $61 \pm 9$ & sienito & $\begin{array}{c}\text { Doranti-Tiritan } \\
\text { (2013) }\end{array}$ \\
\hline L-3 & $\mathrm{TF}-315$ & $51 \pm 6$ & fonólito & Godoy (2003) \\
\hline L-4 & $\mathrm{TF}-502$ & $51 \pm 5$ & brecha magmática & Franco et al (2005) \\
\hline L-5 & TF-1074 & $48 \pm 10$ & Fonolito & $\begin{array}{c}\text { Doranti-Tiritan } \\
\text { (2013) }\end{array}$ \\
\hline L-6 & TF-1076 & $51 \pm 5$ & Nefelina Sienito & $\begin{array}{c}\text { Doranti-Tiritan } \\
\text { (2013) }\end{array}$ \\
\hline L-7 & TF-1077 & $60 \pm 10$ & Nefelina Sienito & $\begin{array}{c}\text { Doranti-Tiritan } \\
\text { (2013) }\end{array}$ \\
\hline L-8 & TF-1180 & $54 \pm 2$ & Sienito & $\begin{array}{c}\text { Doranti-Tiritan } \\
\text { (2013) }\end{array}$ \\
\hline L-9 & TF-1207 & $43 \pm 3$ & fonolito silicificado & Silva (2010) \\
\hline $\mathrm{L}-10$ & TF-1208 & $60 \pm 4$ & fonolito & Silva (2010) \\
\hline L-11 & TF-1209 & $71 \pm 4$ & fonólito & Silva (2010) \\
\hline L-12 & TF-1211 & $61 \pm 3$ & fonolito & Silva (2010) \\
\hline $\mathrm{L}-13$ & TF-1212 & $63 \pm 4$ & fonolito & Silva (2010) \\
\hline L-14 & TF-1079 & $94 \pm 13$ & Charnokito & $\begin{array}{l}\text { Doranti-Tiritan } \\
\qquad(2013)\end{array}$ \\
\hline L-15 & TF-1080 & $151 \pm 13$ & Charnokito & $\begin{array}{c}\text { Doranti-Tiritan } \\
\text { (2013) }\end{array}$ \\
\hline $\mathrm{L}-16$ & $\mathrm{TF}-503$ & $59 \pm 4$ & gnaisse facoidal & Godoy (2003) \\
\hline $\mathrm{L}-17$ & $\mathrm{TF}-134$ & $337 \pm 27$ & granito & $\begin{array}{l}\text { Doranti-Tiritan } \\
\qquad(2013)\end{array}$ \\
\hline L-18 & $\mathrm{TF}-135$ & $256 \pm 25$ & granito epidotizado & $\begin{array}{c}\text { Doranti-Tiritan } \\
\text { (2013) }\end{array}$ \\
\hline
\end{tabular}


Souza D. H. et al.

\begin{tabular}{|c|c|c|c|c|}
\hline L-19 & $\mathrm{TF}-556$ & $248 \pm 29$ & biotita gnaisse & $\begin{array}{c}\text { Doranti-Tiritan } \\
\text { (2013) }\end{array}$ \\
\hline L-20 & $\mathrm{TF}-557$ & $159 \pm 42$ & gnaisse & $\begin{array}{c}\text { Doranti-Tiritan } \\
\text { (2013) }\end{array}$ \\
\hline L-21 & $\mathrm{TF}-558$ & $105 \pm 13$ & sedimentos & Godoy (2003) \\
\hline L-22 & $\mathrm{TF}-559$ & $175 \pm 20$ & biotita - gnaisse & $\begin{array}{c}\text { Doranti-Tiritan } \\
\text { (2013) }\end{array}$ \\
\hline L-23 & $\mathrm{TF}-667$ & $324 \pm 46$ & $\begin{array}{l}\text { ortognaisse } \\
\text { milonitizado }\end{array}$ & Doranti (2013) \\
\hline L-24 & $\mathrm{TF}-668$ & $299 \pm 27$ & gnaisse & $\begin{array}{c}\text { Doranti-Tiritan } \\
\text { (2013) }\end{array}$ \\
\hline L-25 & $\mathrm{TF}-700$ & $330 \pm 46$ & gnaisse & $\begin{array}{c}\text { Doranti-Tiritan } \\
\text { (2013) }\end{array}$ \\
\hline L-26 & $\mathrm{TF}-702$ & $242 \pm 21$ & granito & $\begin{array}{l}\text { Doranti-Tiritan } \\
\qquad(2013)\end{array}$ \\
\hline L-27 & $\mathrm{TF}-703$ & $205 \pm 25$ & granito milonotizado & $\begin{array}{c}\text { Doranti-Tiritan } \\
\text { (2013) }\end{array}$ \\
\hline L-28 & $\mathrm{TF}-505$ & $42 \pm 4$ & granito migmatítico & Franco et al (2005) \\
\hline L-29 & $\mathrm{TF}-506$ & $55 \pm 5$ & sientio & Franco et al (2005) \\
\hline L-30 & $\mathrm{TF}-507$ & $56 \pm 5$ & sientio & Franco et al (2005) \\
\hline L-31 & $\mathrm{TF}-508$ & $46 \pm 4$ & granito & Franco et al (2005) \\
\hline L-32 & $\mathrm{TF}-712$ & $112 \pm 12$ & granito foliado & Doranti (2006) \\
\hline L-33 & $\mathrm{TF}-713$ & $106 \pm 10$ & granodiorito & Doranti (2006) \\
\hline L-34 & $\mathrm{TF}-714$ & $323 \pm 38$ & migmatito & $\begin{array}{c}\text { Doranti-Tiritan } \\
\text { (2013) }\end{array}$ \\
\hline
\end{tabular}

permitiu a identificação de quatro grupos principais de idade, refletindo eventos termais de grande relevância na definição estrutural do relevo regional:

G1 - Idades recentes (até $100 \mathrm{Ma}$ ) com altidudes elevadas e médias (930 a $1537 \mathrm{~m}$ ) - concentradas no Maciço Alcalino Poços de Caldas (MAPC) e algumas áreas no entorno. São correspondentes aos processos de intrusão que originaram o maciço, o qual, segundo a literatura, tem inicio em aproximadamente $89 \mathrm{Ma}$, estendendo-se até cerca de $54 \mathrm{Ma}$ (SONOKI \& GARDA 1988, ULBRICH et al. 2002). As idades semelhantes, no entorno do maciço, teriam sido afetadas pela aureola térmica gerada pela intrusão, rejuvenescendo as idades das rochas do embasamento.

G2 - Idades intermediárias (entre 110 e $170 \mathrm{Ma}$ ) com altitudes médias a baixas (abaixo de $1150 \mathrm{~m}$ ), situadas a leste do MAPC e no entorno do Planalto de São Pedro de Caldas, relacionadas ao embasamento. Este período possui correspondência com a reativação Wealdeniana (ALMEIDA, 1969), relacionada à fragmentação do Gondwana e abertura do oceano Atlântico, a partir de um evento distencional precedido de magmatismo basáltico toleítico. Deste modo, o derramamento basáltico da formação Serra Geral, ocorridos na Bacia do Paraná, entre 137 e 127 Ma (Ar/Ar, MILANI, 2004) teria influência nas amostras, provocando aquecimento e rejuvenescimento das idades. Segundo Gallagher et al. (1998), uma faixa estimada de 1 a $2 \mathrm{~km}$ de espessura de basaltos com baixa condutividade térmica seria suficiente para apagar as idades de traço de fissão em apatitas no embasamento próximo.

G3 - Idades antigas (acima de $200 \mathrm{Ma}$ ) e altitudes elevadas (acima de $1220 \mathrm{~m}$ ), em sua maioria, localiza- 


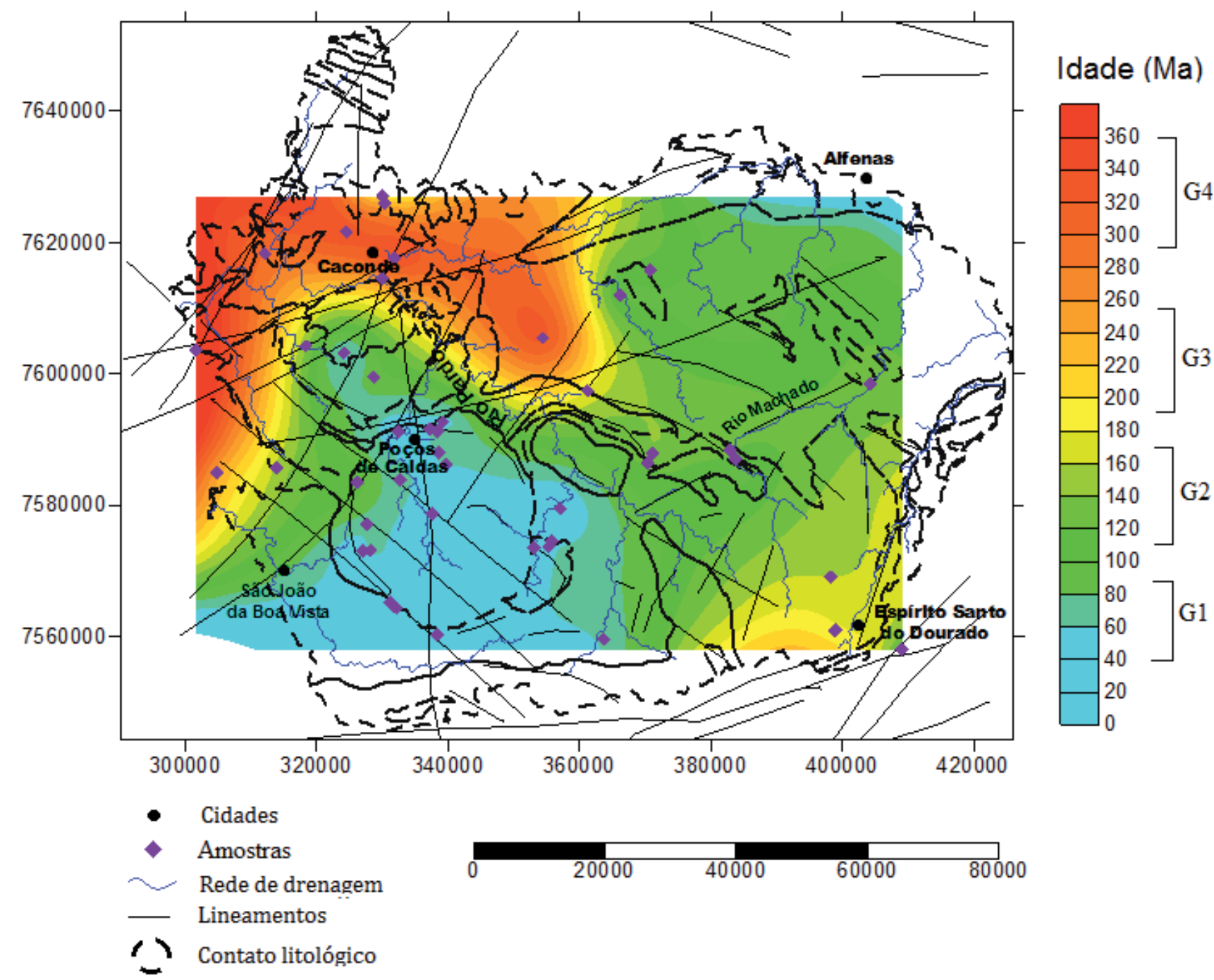

Figura 4 - Mapa de isovalores com distribuição espacial das Idades de TFA. A classificação de idades na legenda refere-se aos grupos identificados no gráfico 1.

das no interior do Planalto São Pedro de Caldas. King (1956) aponta o limite Triássico-Jurassico como início de uma das mais antigas superfícies de erosão - a superfície Gondwana. Hackspacher et al. (2004), por sua vez, aponta esta época como marcador de reativação ao longo da falha de Ouro Fino - Jacutinga, a qual passa imediatamente a sul da área de estudos. Eventos posteriores relacionados à reativação Wealdeniana teriam exumado e preservado estas amostras no topo.

G4 - Idades antigas (acima de $250 \mathrm{Ma}$ ) e altitudes baixas (abaixo de $1000 \mathrm{~m}$ ) - localizadas a norte e oeste do MAPC, na Zona Cristalina do Norte - referentes a rochas do embasamento. Estas amostras possuem idades correlatas a deposição da superseqüencia Gon- dwana I, na Bacia do Paraná (MILANI, 1997, 2004). A área é limitada a oeste pela borda erosiva da referida bacia sedimentar, de modo que pode constituir-se na superfície Itaguá (ALMEIDA, 1964), de idade pré-permiana, antecedente a deposição da sequência, exumada. Assim sendo, em hipótese, a idade obtida seria o registro na apatita do aquecimento causado pela deposição sedimentar sobre a superfície Itaguá.

Além da identificação dos eventos térmicos influêntes na região, a definição destes grupos e sua disposição topografica pode auxiliar na compreensão da dinamica evolutiva do relevo regional. De acordo com Braun et. al. (2002), sob condições termais da crosta em estado estacionário (steady-state), as idades obtidas por 


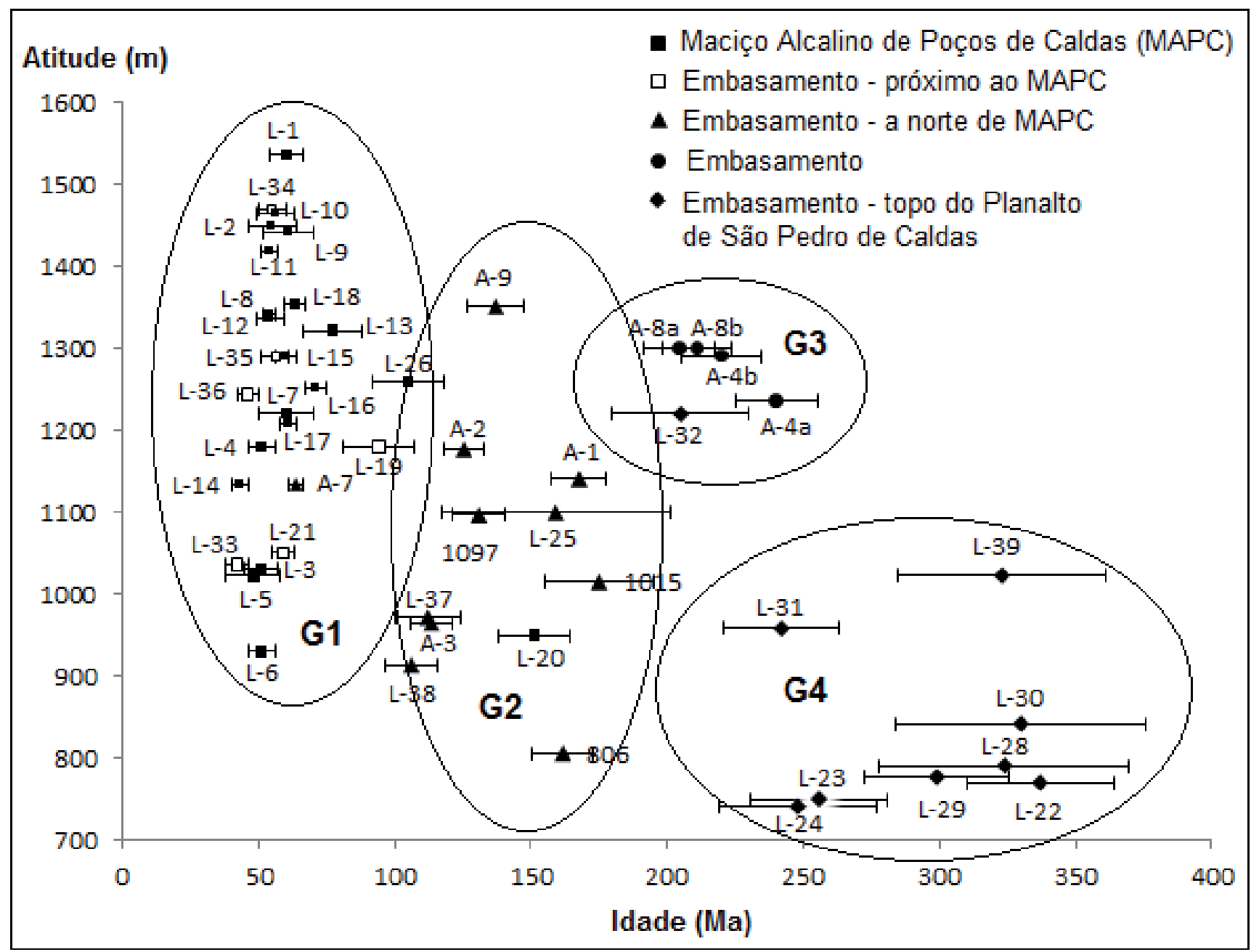

Gráfico 1 - Relação Idade - Altitude

traço de fissão em apatita devem aumentar linearmente com a elevação, isto porque as amostras exumadas em áreas topograficamente elevadas teriam passado pela Zona de Annealing Parcial $\left(120^{\circ}\right.$ a $\left.60^{\circ}\right)$ anteriormente as encontradas em áreas baixas.

Nos resultados apresentados, esta premissa é confirmada pelo planalto São Pedro de Caldas e entorno (Grupo 2 e 3), com idades antigas no interior do planalto elevado, e idades mais recentes no seu entorno. Entretanto, em Poços de Caldas a lógica é invertida. Por conta da intrusão alcalina, responsavel por alçar a região e rejuvenescer as amostras do embasamento, idades recentes são encontradas no interior do maciço (Grupo 1) enquanto as idades mais antigas situam-se em áreas externas (Grupo 4), em locais de baixa topográfia. Deste modo, temos duas regiões próximas, com altitudes semelhantes, mas com idade e dinamica diferente.

\section{2 - Índice Relação Declividade - Extensão dos canais de drenagem - RDE}

Foi calculado o RDE para 1103 segmentos de drenagens, que abrangem todos os canais de terceira, quarta, quinta, sexta e sétima ordem, de acordo com o método de Strahler. A tabela 4 contém a estatística descritiva dos dados e o gráfico 2o histograma de frequência relativa dos valores.

A média de RDE para toda a área de estudos ficou em 105.59. O elevado desvio padrão - 112.93 - é indicativo de que há uma grande variação de valores, sugerindo assim, a presença de anomalias de drenagens na região. O valor máximo - 1458, muito superior a média comprova esta hipótese.

Como se observa no histograma de frequência, quase $67 \%$ dos segmentos de drenagens possuem RDE 
Tabela 4 - Estatística descritiva dos dados de RDE

\begin{tabular}{|cccccc|}
\hline \multicolumn{5}{|c|}{ RDE } \\
\hline Observações & Média & $\begin{array}{c}\text { Erro } \\
\text { Padrão }\end{array}$ & Desvio Padrão & Mínimo & Máximo \\
1103 & 105.59 & 3.40 & 112.93 & 0 & 1458 \\
\hline
\end{tabular}

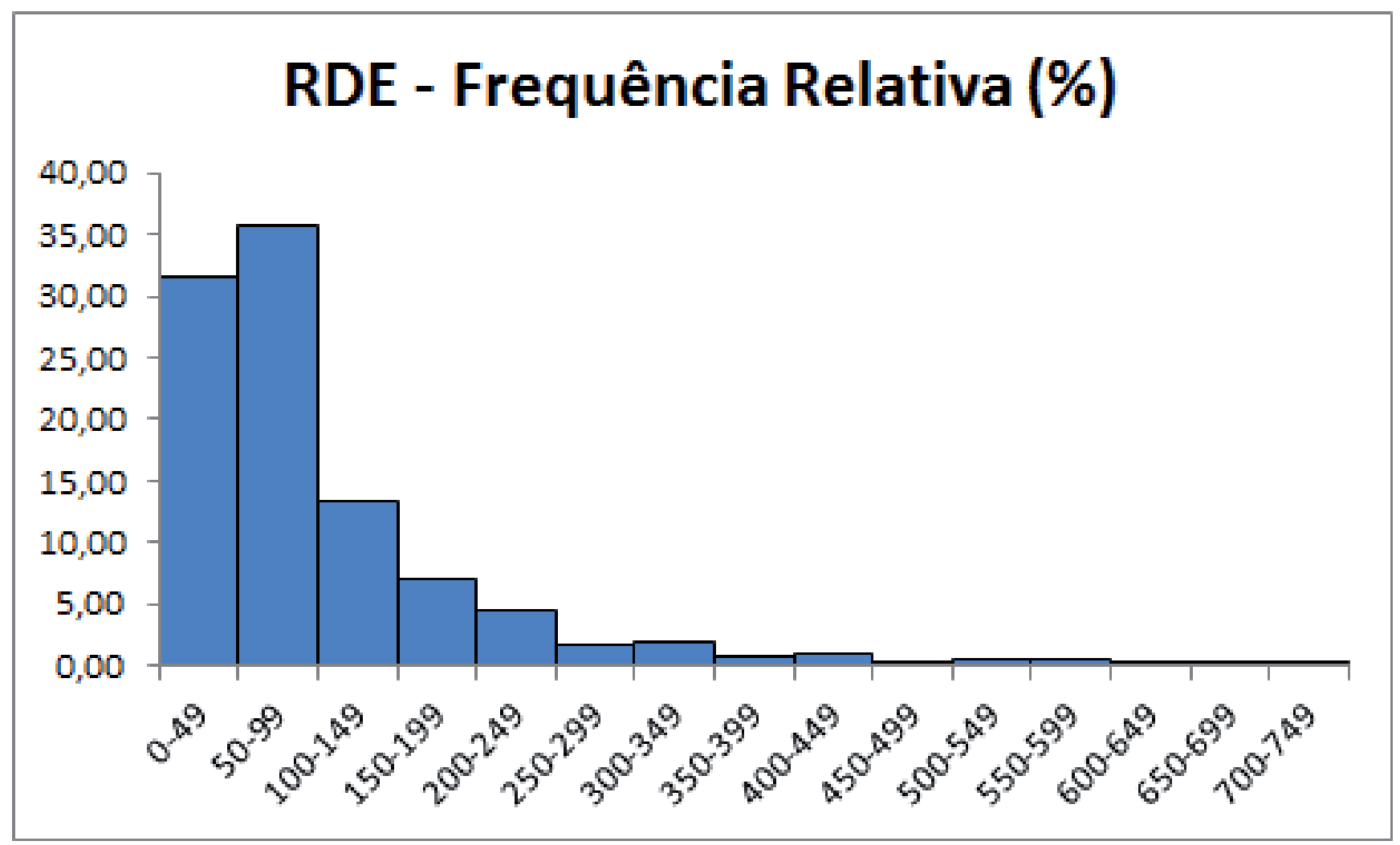

Gráfico 2 - Histograma de frequência - RDE

abaixo da média, configurando os canais adaptados a estrutura, com pouco poder erosivo. Cerca de $13 \%$, fica em torno da média e os restante $20 \%$, valores de RDE elevados, sendo que destes, $16 \%$ concentra-se entre 150 e 350 e $4 \%$ possuem valores extremamente altos, alguns dos quais atingindo valores que ultrapassam a 600 e, em um caso isolado, chega até 1458.

Para visualizar e detectar essas anomalias, bem como para inferir a respeito da dinâmica de evolução do relevo, foi confeccionado um mapa com a espacialização dos valores de RDE através do método de interpolação Vizinhos Naturais, utilizando o ponto central de cada segmento de drenagem, como ponto amostrado - Figura 5.

Comparando o mapa de RDE com o mapa topográfico (Figura 1), identificamos como tendência a concentração de valores altos nos limites de áreas elevadas (pontos de maior declividade), em contraponto aos valores baixos encontrados tanto no interior destas áreas, quanto nas regiões adjacentes, com menores altitudes. Como principal exemplo, temos o dique anelar, individualizando o Planalto de Poços de Caldas, e, de maneira mais sutil, o Planalto São Pedro de Caldas, limitado pelo RDE principalmente na borda NE, onde o Rio Machado passa a seguir esta direção, e a SE, nas proximidades do município de Espirito Santo do Dourado. Considerando o RDE como indicador de potencial energético dos canais de drenagens, podemos supor processos erosivos atuando de maneira mais incisiva nestes locais, de modo que o interior dos planaltos, em altitudes altas, porém com baixo RDE, mantém-se relativamente preservado. 


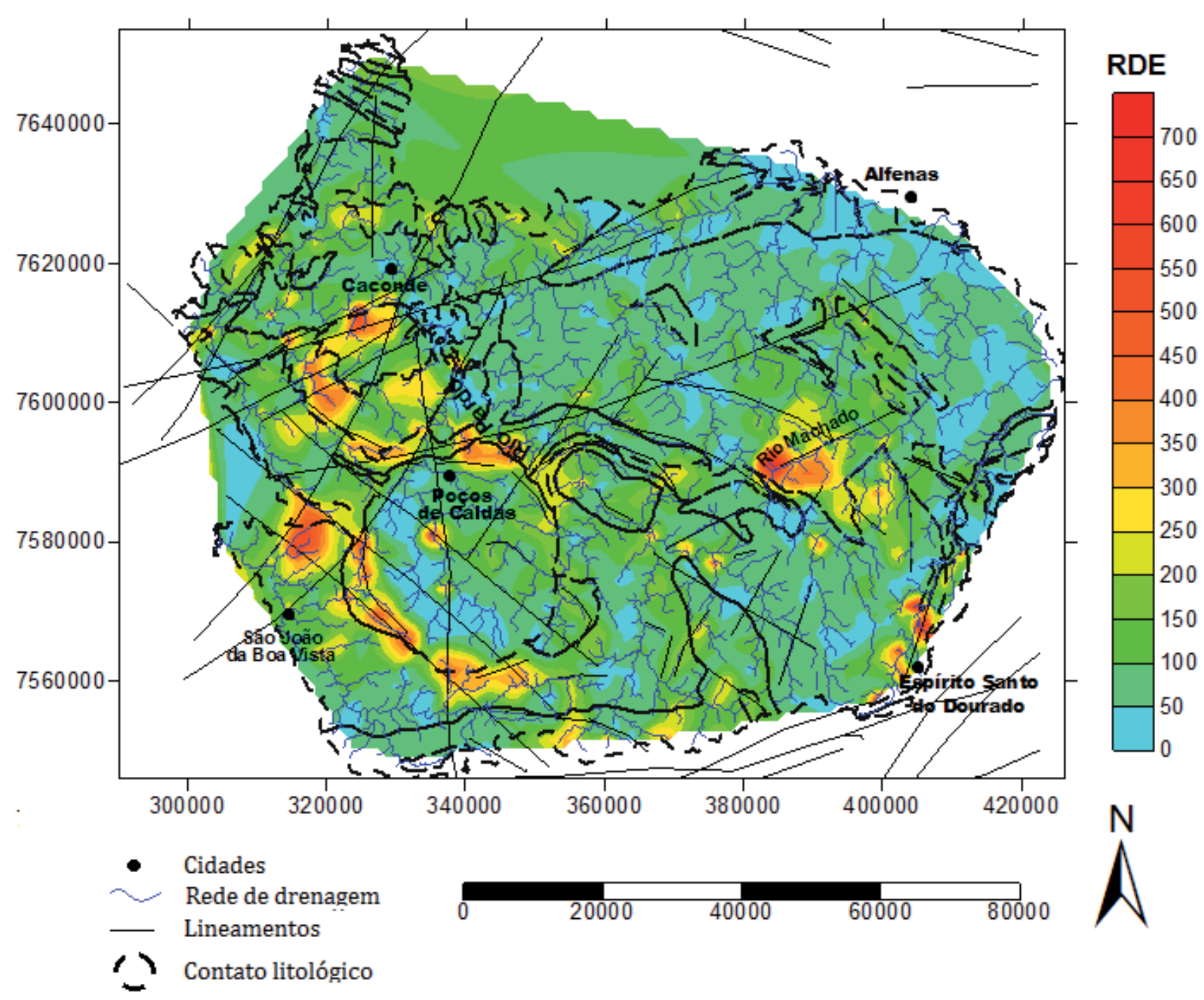

Figura 5 - Mapa de isovalores de RDE

Para esta configuração, é nítido o controle lito-estrutural, através da associação entre alternâncias litológicas e presença de lineamentos estruturais. É notável a influência das rochas alcalinas cretáceas em Poços de Caldas e dos charnoquitos a norte do maciço alcalino. Verificamos também, a importância de lineamentos com direção NE-SW, N-S, NW-SE, além de ENE-SSW. Para Mello et al. (1993), as três primeiras direções mencionadas, são relacionados à formação do lineamento magmático Poços de Caldas-Cabo Frio, responsáveis pela intrusão alcalina na região, no Cretáceo Superior, e a direção ENE-SSW, denominada de Sistema de Falhas Rio Pardo (OLIVEIRA, et aI., 1989; MELLO et al, 1993), aos eventos geradores dos Rifts Cenozóicos do Sudeste do Brasil, no Paleógeno, ainda que de maneira atenuada na região. Segundo estes autores, a atividade tectônica teria prosseguimento após o Paleógeno até os dias atuais, aproveitando as estruturas citadas.

\section{3 - Correlação de dados}

Foram traçados quatro perfis, os quais contemplam topografia, idade de traço de fissão em apatita (TFA), RDE e geologia (Figura 1). O traçado dos perfis foi realizado de maneira que possibilitasse a comparação entre os planaltos de Poços de Caldas (PPC) e de São Pedro de Caldas (PSPC) - Figuras 6 e 7 - e estes dois planaltos com as áreas adjacentes a norte, com topografias menos elevadas - Figuras 8 e 9 . 


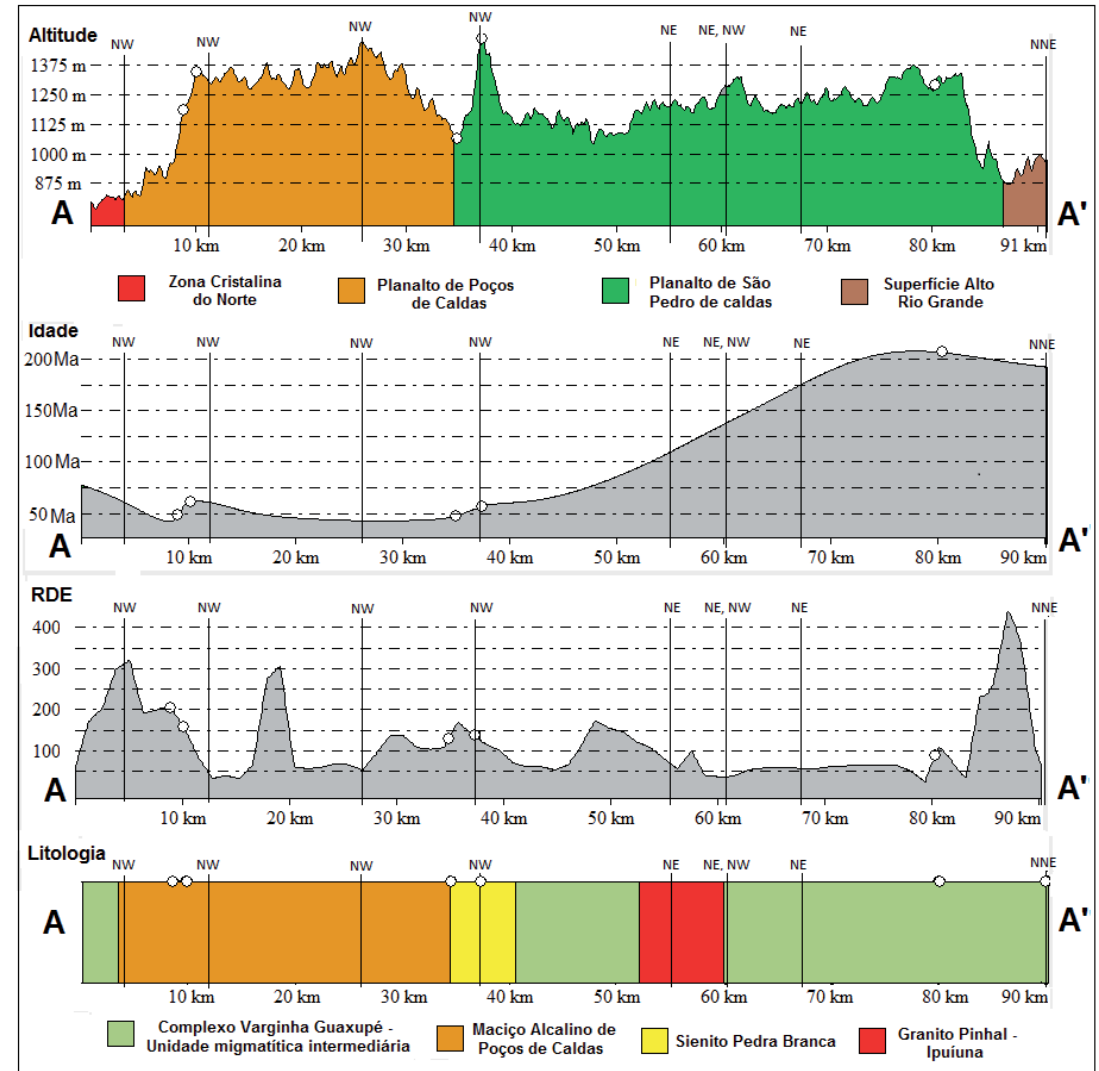

Figura 6 - Perfil A-A'

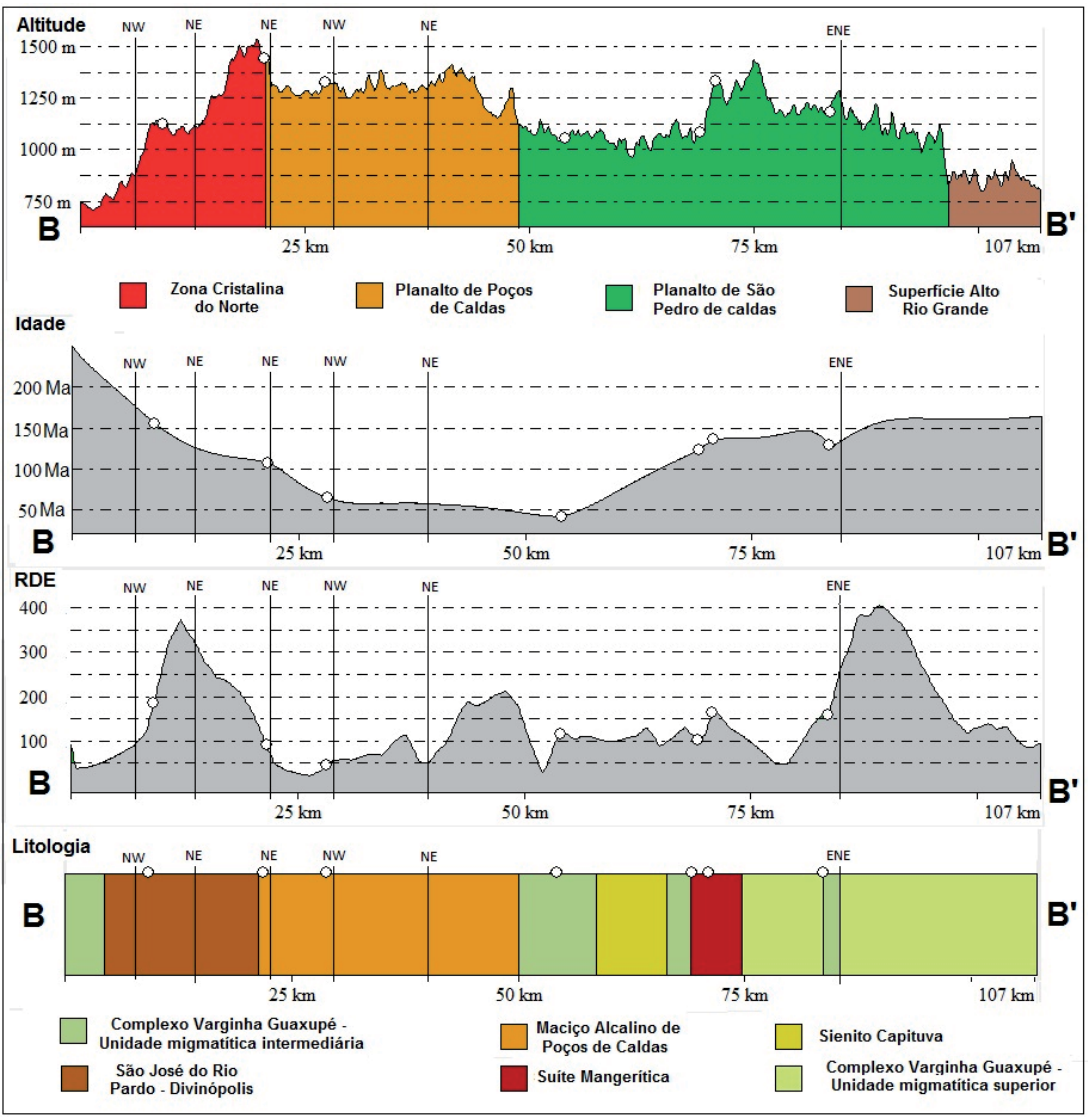

Figura 7 - Perfil B-B' 
Souza D. H. et al.

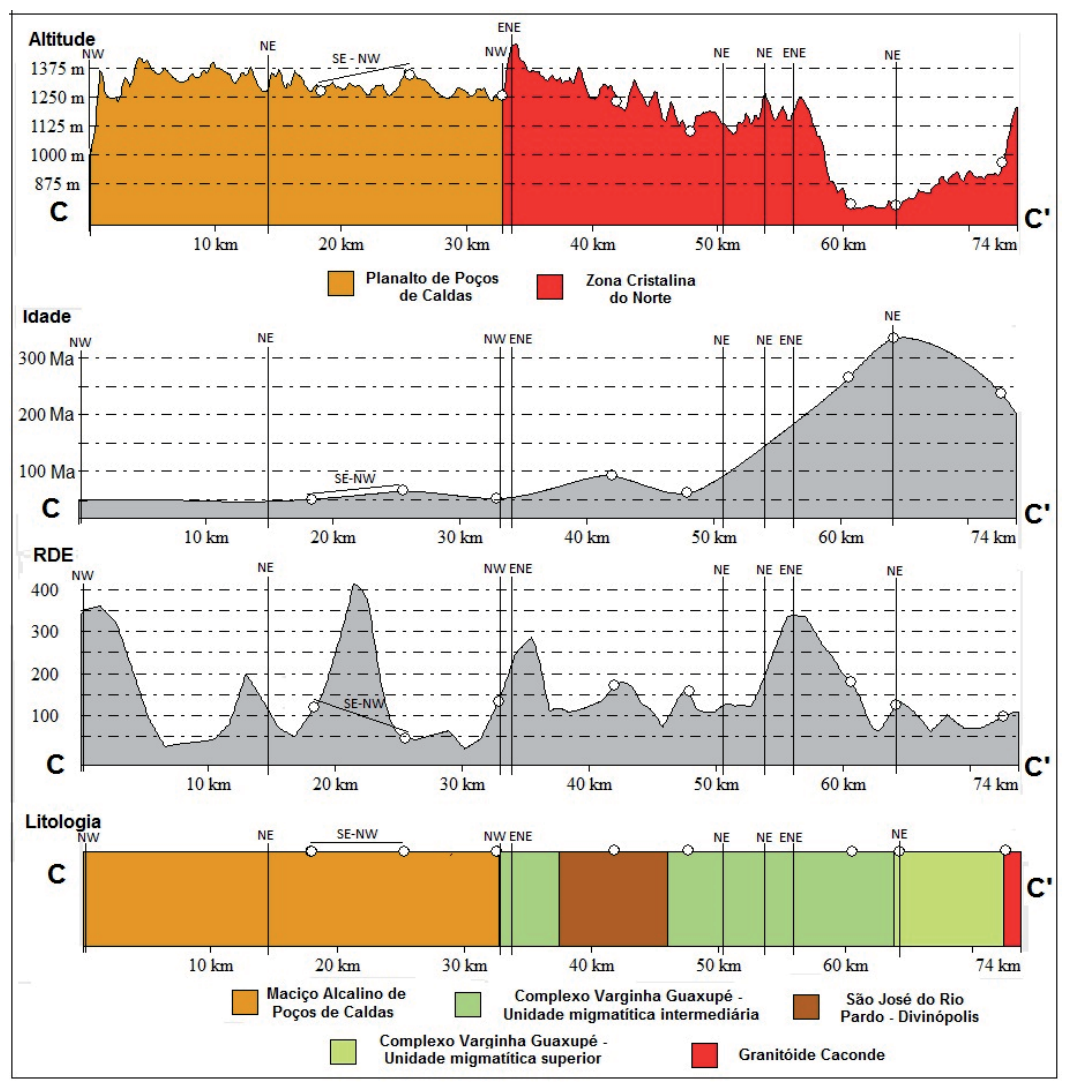

Figura 8 - Perfil C-C'

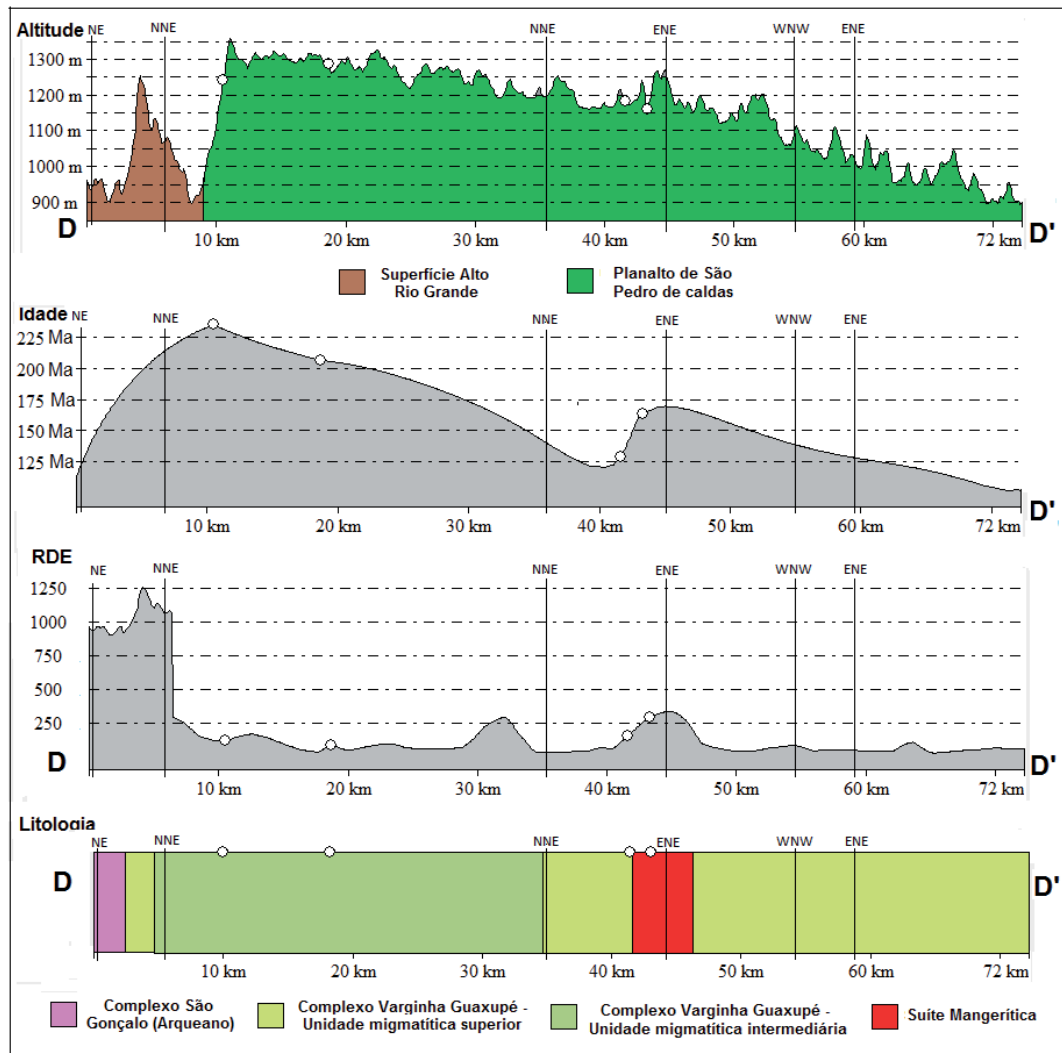

Figura 9 - Perfil D-D' 
A visualização dos perfis permite sintetizar as considerações já realizadas nos itens anteriores:

- Em todos os perfis, a litologia parece marcar os desníveis topográficos e os picos de RDE;

- São frequentes, e também possuem influência marcante na topografia e no RDE os lineamentos de direção NE, NW e ENE;

- Picos de RDE, no interior do PPC podem ser relacionados as estruturas circulares existentes no maciço - perfil A. B e C;

- A interação entre estas direções, associadas a alternâncias litológicas é mais pronunciada no perfil $\mathrm{C}$, que relaciona o PPC, com as áreas da Zona Cristalina do Norte;

- A passagem do PPC para o PSPC, a leste do primeiro, e oeste do segundo, se realiza relativamente de maneira gradual - perfil B;

- Os demais limites do PPC são marcados pelo dique anelar, com considerável desnível topográfico sobre as áreas circunvizinhas, por sua vez, no PSPC, o limite SE, E e NE é marcado por escarpas;

- Ao comparar o PPC e o PSPC, nos perfis A e B, percebemos uma lógica distinta em relação às idades de TFA: enquanto no planalto de Poços de Caldas a curva da idade possui relação inversa com a topografia, em São Pedro de Caldas a curva de idade passa a seguir o desenho da topografia;

- Comparando o PPC com a Zona Cristalina do Norte (ZCN) - perfil C, reafirmamos esta tendência, em altitudes elevadas, tanto em PPC, quanto na região soerguida da ZCN, as idades são mais recentes que $100 \mathrm{Ma}$, contrastando com as regiões rebaixadas da ZCN, com idades antigas, ultrapassando $300 \mathrm{Ma}$;

- Entretanto, no perfil D, que faz o transecto S-N do PSPC, a curva da idade segue a topografia, com idades antigas, superiores a 200 Ma nas áreas elevadas, decrescendo até cerca de 120 Ma, nas áreas rebaixadas.

Assim sendo, temos dois planaltos na região, que apesar de atingem altitudes topográficas semelhantes, possuem forma de evolução diferenciada. Para sua compreensão, recorremos aos eventos que estruturaram em suas características mais gerais o relevo do sudeste brasileiro, primeiramente aqueles ocorridos no Cretáceo Superior (ZALAN e OLIVEIRA, 2005): a sequência de intrusões alcalinas denominada de Alinhamento de
Rochas Alcalinas Poços de Caldas - Cabo Frio devido à passagem da placa sobre uma anomalia térmica, soerguimento generalizado do embasamento, a formação de um megaplanalto regional seguido da atuação da superfície erosiva Sul-Americana.

Neste contexto, o planalto de Poços de Caldas teve origem pela ocorrência de intrusões magmáticas e vulcanismo, produzindo um extenso corpo alcalino, soerguendo a região e criando uma auréola térmica responsável por rejuvenescer o embasamento ao seu entorno. Concomitantemente, as camadas sedimentares da bacia do Paraná, presentes na região no momento anterior a intrusão (ELLERT, 1959; BJÖRNBERG, 1959; ULBRICH e ULBRICH, 1992), seriam erodidas sob a ação da Superfície Sul-Americana e o embasamento pré-cambriano exumado.

Rochas adjacentes ao planalto de Poços de Caldas possuem altitudes e idades semelhantes às rochas alcalinas, porém, como apontado anteriormente, o embasamento a norte do planalto (Zona Cristalina do Norte), fora da influência térmica da intrusão, possui topografia baixa e idades antigas, correlatas a sedimentação da sequência Gondwana I, podendo ser o registro da superfície erosiva antecedente a sedimentação, agora exumada, no caso, a superfície Itaguá descrita por Almeida (1964).

Ao desnivelamento dos blocos de idades distintas, com relação inversa entre topografia e idade, podemos destacar, além do papel da erosão diferencial, a influência de diversas direções de lineamentos morfoestruturais que se cruzam a nordeste da área de estudos, sobretudo, aos de direção ENE relacionados ao sistema de Falhas Rio Pardo. Como se observa na figura 5, valores altos de RDE, além de delimitar os blocos alto e baixo, são fortemente marcados por essa confluência de lineamentos. Alguns autores (ALMEIDA FILHO E PARADELLA, 1977; OLIVEIRA et al, 1989; MELLO et al,1993) relacionam estes lineamentos aos processos geradores dos Riftes Cenozóicos do Sudeste do Brasil, a partir do Paleógeno, ainda que de maneira mais atenuada que nas localidades próximas a região litorânea.

Em contrapartida, no planalto São Pedro de Caldas, o embasamento teria sofrido apenas um soerguimento epirogenético pelo alçamento da isoterma pela possível passagem da placa pela anomalia térmica. A influência da anomalia térmica foi verificada em histórias térmicas de amostras a leste no planalto São Pedro 
de Caldas, em regiões baixas próximas ao escarpamento, analisadas por Franco (2003)- gráfico 3 , que registram inicialmente episódios de resfriamento lento no limite Jurássico - Cretáceo, associados a soerguimento - ciclos de erosão relacionados a primeira fase da reativação Wealdeniana, seguido de um aquecimento em torno de 70 Ma, idade correspondente aos processos de intrusão do Maciço Alcalino de Poços de Caldas.

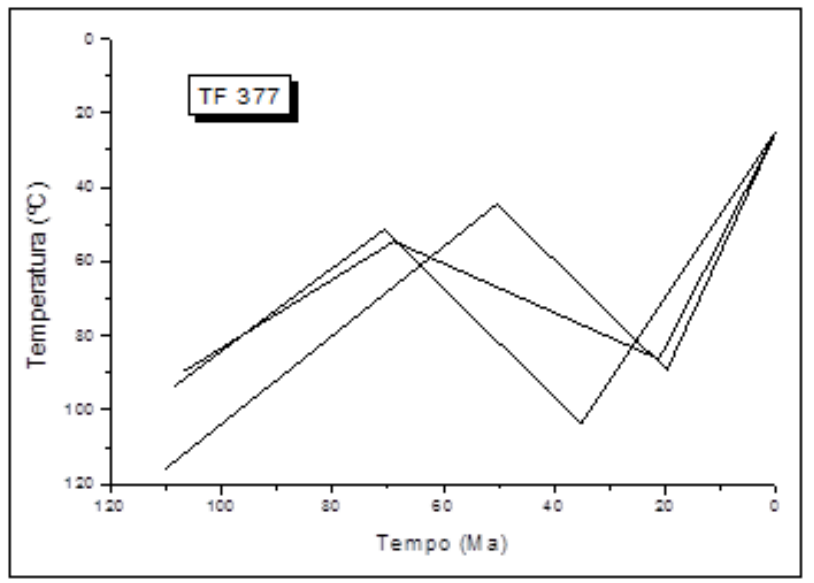

Gráfico 3 - História Térmica da amostra TF-377. Fonte: Franco 2003.

Sob tal influência térmica, de maneira similar a toda região sudeste, o embasamento soergueu formando o Planalto São Pedro de Caldas, que viria a sofrer a ação erosiva que formaria a Superfície Sul Americana. A curva de idade de TFA, em conformidade com a topografia, com as idades decrescendo conforme se diminui a topografia, como analisado nos perfis acima atestaria a homogeneidade do processo em toda a área, e o caráter epirogenético do soerguimento.

No entanto, alguns fatos indicam uma forma de evolução mais complexa. Apesar do decréscimo linear das idades, dois grupos, com eventos térmicos distintos são reconhecidos: o G2, assinalado como correlato a Reativação Wealdeniana (em torno de $130 \mathrm{Ma}$ ), em altitudes intermediarias, e o G3, no topo do planalto, com idades acima de $200 \mathrm{Ma}$, podendo ser relacionada a reativação da falha de Ouro Fino (HACKSPACHER et al., 2004). Os dois conjuntos de idades parecem ser separados, de sudeste a norte do planalto por escarpas de falha, com desenho coincidente em parte ao contato litológico, porém relativamente deslocados em relação a estes.

Estas escarpas estão marcadas por valores de RDE elevados, em contraposição ao interior do planalto e nas áreas externas rebaixadas, indicando, para os dias atuais, processos erosivos atuantes nas escarpas, preservando as demais áreas. Tendência de evolução esta que é reafirmada por dados mais precisos realizados em regiões próximas: a mensuração da produção do isótopo cosmogênico ${ }^{10}$ Be indicou no Sul da Serra do Espinhaço e região do Quadrilátero Ferrífero- MG (BARRETO et a., 2013; SALGADO, et al., 2007) e no Contexto da Serra da Mantiqueira - sudeste do Brasil (CHEREM et al., 2012), baixas taxas de denudação, sendo abaixo de 10 $\mathrm{m}$ por milhão de anos (abaixo de $5 \mathrm{~m}$ no quadrilátero ferrífero) em patamares elevados e entre 10 e $20 \mathrm{~m}$ por milhão de anos em regiões escarpadas.

Ainda para o Quadrilátero Ferrífero, perfis de alteração profundos, em altitudes elevadas, foram datadas por ${ }^{40} \mathrm{Ar} /{ }^{39} \mathrm{Ar}$ com idades entre 62 - $14 \mathrm{Ma}$ (SPIER et al., 2006) e 67.5-13 Ma (CARMO E VASCONCELOS, 2004), indicando baixas taxas de denudação ao longo do tempo e preservação de paisagens antigas. Adicionalmente, Hiruma et al (2010) registrou idades acima de 200 Ma no topo do planalto da Bocaina, na Serra do Mar. Segundo estes autores, estas idades naquela localidade indicam baixa denudação e ausência de influência térmica dos derrames da formação Serra Geral; ainda, em conformidade com as idéias de Ab’Saber (2000), estas regiões estariam em altitudes elevadas mesmo antes da ruptura continental e soerguimento continuo aliado a presença de knickpoints estruturais teriam desempenhado papéis importantes na preservação destas área.

Se esta tendência se confirma no planalto de São Pedro de Caldas (o que pode ser sugerido pelas idades antigas de TFA e o padrão de valores de RDE), temos uma forma de evolução por retração de escarpas, de modo que as idades antigas permanecem relativamente preservadas no interior do planalto. Assim, aliado ao soerguimento epirogenético continuo, as escarpas teriam papel decisivo na delimitação dos blocos topográficos. Quanto origem das escarpas, tem-se a associação entre contatos litológicos e os lineamentos estruturais, cujas reativações, foram descritas por Mello et al. (1993), de modo que as direções NE-SW, N-S, NW-SE seriam associadas aos processos de intrusão magmática e ENE -SSW, de grande importância no RDE do rio Machado (figura5), atrelado aos Rifts Cenozóicos do Sudeste do Brasil. A continuidade de processos tectônicos, ao longo do Neógeno, reaproveitando estas estruturas, revitalizariam as escarpas e estabeleceriam novos patamares, reafirmando o mecanismo de evolução. 


\section{5 - Conclusões}

A configuração do relevo atual é produto de uma construção policíclica e complexa que se da através do tempo em uma sucessão de eventos que se superpõem uns aos outros. Esta superposição não se da de maneira aleatória e independente, cada evento é condicionado por eventos pretéritos, ao mesmo tempo em que se torna condicionante de eventos futuros. Além disso, processos correntes não atuam apenas de maneira passiva àqueles que os precederam, agem também de maneira independente de modo a exumá-los, reativa-los, preservá-los ou a extinguir seu registro.

Assim, verificamos a relevância da integração entre metodologias que abrangem longos períodos de tempos com aquelas que denotam a dinâmica atual. Neste trabalho identificamos que compartimentos topográficos, fortemente demarcados pela dinâmica da rede de drenagem, isolam rochas que registram eventos térmicos de idade e natureza distinta.

Dois planaltos foram analisados e comparados, revelando cada um, uma dinâmica própria, denunciada pela relação da topografia com a curva na idade: idades recentes nas áreas elevadas do Planalto de Poços de Caldas e idades antigas nas regiões rebaixadas da Zona Cristalina do Norte, situação inversa a do Planalto de São Pedro de Caldas, onde a idade decresce conforme diminui a topografia. A diferença de comportamento se explica pela gênese do soerguimento de cada um, durante o Cretáceo Superior, se magmatismo alcalino originou o primeiro planalto, o segundo teve sua origem relacionada a um soerguimento epirogênico. Em ambos os casos, a atividade tectônica ao longo do Cenozoico teve papel de destaque no desnivelamento e na compartimentação dos blocos topográficos.

A análise do Índice de Relação Declividade Extensão do Canal, efetuada sobre uma rede de drenagem que responde a dinâmica atual do relevo, mostrou-se interessante no sentido em que possibilitou entender como essa dinâmica se relaciona aos eventos térmicos antigos registrados. A distribuição de valores altos e baixos indica onde os processos erosivos se concentram e quais as áreas estáveis. Identificamos assim o sentido da evolução do relevo (escarpas), superfícies erosivas antigas preservadas e exumadas, além da importância dos eventos tectônicos e magmáticos na compartimentação do relevo.

\section{Agradecimentos}

FAPESP (processo 2011/05373-4) e CNPq pelo suporte financeiro ao longo da pesquisa. Ao grupo de cronologia da UNESP de Rio Claro, pelas amostras cedidas e suporte técnico para a realização da pesquisa.

\section{Referencias}

AB' SÁBER, A.N. Summit surfaces in Brazil. Revista Brasileira de Geociências 30 (3), 515-516, 2000.

ALMEIDA, F. F. M. Geologia do Estado de São Paulo. IGG, Boletim N. ${ }^{\circ}$ 41, 263 p, 1964.

ALMEIDA, F. F. M. Diferenciação tectônica da Plataforma Brasileira. In: CONGRESSO BRASILEIRO DE GEOLOGIA, 23., 1969, Salvador. Anais... Salvador: SBG, p. 29-46, 1969.

ALMEIDA, F. F. M.; CARNEIRO, C.D.R.; MIZUSAKI, A.M.P. Correlação do magmatismo das bacias da margem continental brasileira com o das áreas emersas adjacentes. Revista Brasileira de Geociências, 26 (3): 125-138, 1996.

ALMEIDA, F. F. M.; BRITO NEVES, B.B.; CARNEIRO, C.D.R. The origin and evolution of the South American Platform. Earth Science Reviews, 50: 77-111, 2000.

ALMEIDA-FILHO R. \& PARADELLA W. R. 1977. Estudo do Maciço Alcalino de Poços de Caldas através de imagens de LANDSAT com ênfase em mineralizações radioativas. Dissertação de Mestrado, Instituto Nacional de Pesquisas Espaciais, 130 págs.

BARRETO, H. N; VARAJÃO C. A. C; BRAUCHER R.; BOURLÈS, D. L.; SALGADO, A. A.R, VARAJÃO, A. F.D.C. Denudation rates of the Southern Espinhaço Range, Minas Gerais, Brazil, determined by in situ-produced cosmogenic beryllium-10. Geomorphology, 191 (2013) 1-13. 2013.

BJORNBerG, A.J.S. Rochas elásticas do Planalto de Poços de Caldas. BoI. Fac. Fil. Ciên. Letras - USP Geologia n!' 18,pp. 64-122, São Paulo, 1959.

BISHOP, P. Long-term landscape evolution: linking tectonics and surface processes. Earth Surface Processes and Landforms, v. 32, p. 329-365, 2007.

BRAUN, J.. Quantifying the effect of recent relief changes on age-elevation relationships. Earth and Planetary Sciences Letters 200:331-343, 2002.

CARMO, I.O., VASCONCELOS, P. Geochronological evidence for pervasive Miocene weathering, Minas Gerais, Brazil. Earth Surface Processes and Landforms 29, 1303-1320, 2004. 
CAVALCANTE, et al. Relatório Final de Geologia - Ministério das Minas e Energia. Departamento Nacional da Produção Mineral. Brasília, 1979.

CHEREM, L.F.S., VARAJÃO, C.A.C., BRAUCHER, R., BOURLÈS, D., SALGADO, A.A.R., VARAJÃO, A.F.D.C. Long-term evolution of denudational escarpments in southeastern Brazil. Geomorphology 173-174, 118-127, 2012.

DORANTI C. Estrutura da Paisagem no Leste de São Paulo e Sudoeste de Minas Gerais: Relações Entre Superfícies de Erosão e Termocronologia por Traços de Fissão. $106 f$. Dissertação de Mestrado. Universidade Estadual Paulista, Rio Claro-São Paulo, 2006.

DORANTI-TIRITAN, C. Evolução Geomórfica e Modelagem Termocinemática 3D da Região do Maciço Alcalino de Poços de Caldas (SP/MG). Tese de Doutorado apresentada junto ao Programa de Pós-Graduação em Geologia Regional IGCE UNESP Rio Claro, 2013.

ELLERT R.. Contribuição à geologia do Maciço Alcalino de Poços de Caldas. São Paulo, Fac. Filos. Ciên. Let./USP, Boletim 237, Geologia 18: 5 - 63, 1959.

ETCHEBEHERE, M. L. C. ; SAAD, A. R. ; PERINOTTO, J. A. J. ; FULFARO, V. J. Aplicação do Índice "Relação DeclividadeExtensão - RDE” na Bacia do Rio do Peixe (SP) para detecção de deformações neotectônicas. Revista do Instituto de Geociências - USP - Série Científica, São Paulo, v. 4, n. 2, p. 43-56., 2004.

FELLIN, M. G.; ZATTIN, M.; PICOTTI, V. Relief evolution in northern Corsica (western Mediterranean): Constraints on uplift and erosion on long-term and short-term timescales. JOURNAL OF GEOPHYSICAL RESEARCH, VOL. 110, F01016, doi:10.1029/2004JF000167, 2005.

FRANCO A.O.B. História Térmica e Denudação do Maciço Alcalino de Poços de Caldas (SP/MG) e adjacências: área sul. Monografia de Trabalho de Formatura, Instituto de Geociências e Ciências Exatas, UNESP, 97 p., 2003.

FRANCO, A. O. B. ; HACKSPCHER, P. C. ; GODOY, D. F. ; RIBEIRO, L. F. B.; GUEDES, S. História Térmica do Maciço Alcalino de Poços de Caldas (SP/MG) e adjacências através da Análise de Datação por Traços de Fissão em apatitas. Revista Brasileira de Geociências, v. 35, n. 3, p. 351-358, 2005.

FRANCO-MAGALHÃES, A. O. B. Exumação tectônica e evolução associada do relevo no Arco de Ponta Grossa, sul-sudeste do Brasil. Tese de Doutorado, Programa de PósGraduação em Geologia Regional, Unesp - Rio Claro, 2009.
FREITAS, R.O. Jazimentos de rochas alcalinas da ilha de São Sebastião. São Paulo, Fac. Fil. Ciên. Letras, Boletim 85, Geologia 3, 244 p., 1947.

GALLAGHER, K., BROWN, R.W.; JOHNSON, C. Fission track analysis and its application to geological problems. Annual reviews of Earth Planetary Sciences, v. 26, p. 519-572, 1998.

GODOY, D. F. de. Historia Térmica e Denudação do Maciço Alcalino de Poços de Caldas e Circunvizinhanças: Área Norte. Trabalho de Graduação - IGCE-UNESP, Rio Claro-SP, 2003.

GOLTS, S. AND ROSENTHAL, E. Morphotectonic Methods To Infer Groundwater Flow Under Conditions Of Scarce Hydrogeological Data-The Case Of Northern Arava, Israel, Hydrogeol. J., 1, 5-19, doi:10.1007/s100400050245, 1992.

GROHMANN, C. H.; RICCOMINI, C; CHAMANI M. A. C. Regional scale analysis of landform configuration with base-level (isobase) maps. Hydrol. Earth Syst. Sci., 15, 1493 1504, 2011.

HACK, J. T. Stream profile analysis and stream gradient index. Journal Research of U. S. Geological Survey, v. 1, 421 - 429, 1973

HACKSPACHER, P.C.; RIBEIRO, L. F. B.; RIBEIRO, M.C.S.; FETTER, A.H.; HADLER NETO, J.C.; TELLO SAENZ, C.A.; DANTAS, E.L. Consolidation and Break-up of the South American Platform in Southeastern Brazil: Tectonothermal and Denudation Histories. Gondwana Research, v. 7, n. 1, p. 91 - 101, 2004.

HACKSPACHER , P. C., GODOY, D. F., RIBEIRO, L. F. B., HADLER NETO, J. C., , A. O. B. Modelagem térmica e geomorfologia da borda sul do Cráton do São Francisco: termocronologia por traços de fissão em apatita. Revista Brasileira de Geociências. 37(4 - suplemento): 76-86, 2007.

HAMZA V.M., FRANGIPANI A., BECKER E.A., MIOTO J.A. Mapas geotermais do Brasil. Relatório interno do Instituto de Pesquisas Tecnológicas, SP. Brasil, IPT - nº 27069, 1989.

HEILBRON, M.; PEDROSA-SOARES, A.C.; CAMPOS NETO, M. C.; SILVA, L.C.; TROUW, R.A.J.; JANASI, V.A. Província Mantiqueira, p. 204-234. In: MANTESSO-NETO, V.; BARTORELLI, A.; CARNEIRO, C.D.R.; BRITO-NEVES, B.B.; (org) Geologia do Continente Sul-Americano: Evolução da Obra de Fernando Flávio Marques de Almeida, São Paulo, Beca, 647p. 2004.

HIRUMA, s. t. et al. Denudation history of the Bocaina Plateau, serra do Mar, southeastern Brazil: Relationships to Gondwana breakup and passive margin development. Gondwana Research. 
v. 18, n. 4, p. 674-87. nov. 2010.

HODGKINSON, J.H. McLOUGHLIN, S., COX, M.. The influence of geological fabric and scale on drainage pattern analysis in a catchment of metamorphic terrain: Laceys Creek, southeast Queensland, Australia. Geomorphology 81, 394-407, 2006.

HURFORD, A. J. \& GREEN, P. F. The zeta age calibration of fission track dating. Isotope Geosci. 1, 285-317. 1983.

KELLER, E. A.; PINTER, N. Active tectonics - eartquakes, uplift, and landscape. New Jersey: Prentice Hall, 338 p. 1996.

KING, L.C. A Geomorfologia do Brasil Oriental. Revista Brasileira de Geografia, V.18, N.2, P.147-265, 1956.

MACKTELOW, N.S.; GRASEMANN, B. Time-dependent effects of heat advection and topography on cooling histories during erosion. Tectonophysics, v. 270, p. 167-195, 1997.

MELO, M.S. de; STEIN, D.P.; PONÇANO, W.L.; BISTRICHI, C.A. Neotectônica da área do Alto Rio Pardo (SP e MG). São Paulo: Revista do Instituto Geológico, 14(2),27-38. 1993.

MILANI, E.J. Evolução tectono-estratigráfica da Bacia do Paraná e seu relacionamento com a geodinâmica fanerozóica do Gondwana sul-ocidental. Instituto de Geociências, Universidade Federal do Rio Grande do Sul, Tese de Doutoramento, 255 p. 1997.

MILANI E.J. Comentários sobre a origem e a evolução tectônica da Bacia do Paraná. In: MONTESSO-NETO, V., BARTORELLI A., CARNEIRO C.D.R., BRITO-NEVES B.B. Geologia do Continente Sul-Americano - evolução da obra de Fernando Flávio Marques de Almeida. Ed. Becca, p.265-279. 2004.

OLIVEIRA, M. A. F. E ALVES, F. R.; Sedimentação associada ao vulcanismo alcalino de Poços de Caldas (Divinolãndia, SP). Boletim IG. Instituto de Geociências, USP, V. 6: 13-19, 1975.

OLIVEIRA, M.A.E de, MORALES, N., ZANARDO, A., CARVALHO, S.G. de, MANIAKAS, S. Projeto: mapeamento geológico em 1:25.000 do quadrante noroeste da Folha Caconde; relatório final. UNESP - PRÓ-MINÉRIO. Rio Claro: UNESP - PRÓ-MINÉRIO. 170p. 1989.

PAZZAGLIA, F. J., e BRANDON, M. T. A fluvial record of long-term steady state uplift and erosion across the Cascadia forearc high, western Washington State, American Journal of Scienc, 301, 385-431. 2001.

PAZZAGLIA, F. J.; GARDNER, T. W.; MERRITTS, D. J. Bedrock fluvial incision and longitudinal profile development over geologic time scales determined by fluvial terraces, in
Rivers Over Rock: Fluvial Processes in Bedrock Channels, Geophys. Monogr. Ser., vol. 107, editado por K. J. Tinkler e E. E. Wohl, pp. 207-235, AGU, Washington, D. C. 1998.

PONÇANO, W. L., CARNEIRO, C. D. R., BISTRICHI, C. A., ALMEIDA, F. F. M., PRANDINI, F. L. Mapa geomorfológico do Estado de São Paulo. São Paulo. Instituto de Pesquisas Tecnológicas do Estado de São Paulo. 2: 94. 1981.

REINERS, P.W.; BRANDON, M.T. Using the Thermochronology to understando orogenic erosion. Annual Review of Earth and Planetary Science, v. 34, p. 419-466, 2006.

ROSS, J. L. S. O Registro Cartográfico dos Fatos Geomórficos e a Questão da Taxonomia do Relevo . Revista do Departamento de Geografia (USP), São Paulo, v. 06. 1992.

SALGADO, A.A.R.; VARAJÃO, C.A.C., COLIN, BRAUCHER, R F., VARAJÃO, A.F.D.C., NALINI JR., H.A., CHEREN, L. F. S., MARENT, B. R.; BRINDUSA, C. B. Estimativa das taxas de erosão das terras altas da Alta bacia do rio das Velhas no Quadrilátero Ferrífero: implicações para a evolução do relevo. Revista Brasileira de Geomorfologia, v.8, n.2, p.3-10, 2007.

SILVA. J. S. Reconstrução termocronologica do maciço alcalino de Poços de Caldas e áreas adjacentes por traços de fissão e (U-Th-Sm)ไhe em apatitas e zircão. Trabalho de Conclusão de Curso. Rio Claro, 2010.

SONOKI, I. K. e GARDA G.M. Idades K/Ar de Rochas Alcalinas do Brasil Meridional e Paraguai Oriental: Compilação e Adaptação a novas constantes de decaimento. Instituto de Geociências/ USP, Boletim Série Científica, (19):63-85. 1988.

SPIER, C.A., VASCONCELOS, P.M., OLIVEIRA, S.M.B. 40Ar/39Ar geochronological constraints on the evolution of lateritic iron deposits in the Quadrilátero Ferrífero, Minas Gerais, Brazil. Chemical Geology 234, 79-104. 2006.

STRAHLER, A. N. Quantitative analysis of watershed geomorphology. Geophysical Union Trans., v.38, p.912-920, 1957.

STUWE, K.; WHITE, L.; BROWN, R. The influence of eroding topography on steady-state isotherms: Application to fissiontrack analysis, Earth and Planetary Science Letters., 124, $63-74.1994$.

STUWE, K.; HINTERMULLER, M. Topography and isotherms revisted: the influence of laterally migrating drainage divides. Earth and Planetary Science Letters, v. 184, p. 287-303, 2000.

SUMMERFIELD, M.A. Global Geomorphology. Longman Scientific and Technical. Co-published by JohnWiley and Sons Inc., New York, 537 pp. 1991. 
TELLO SAENZ, C. A.; HACKSPACHER, P. C.; HADLER NETO, J. C.; IUNES, P. J.; GUEDES, S.; RIBEIRO, L. F. B.; PAULO, S. R. Recognition of cretaceous, Paleocene and neogene tectonic reactivation through apatite fission-track analysis in precambrian areas of southeast Brasil: association with the opening of the south Atlantic Ocean. Journal of South American Earth Sciences, Oxford, v. 15, n. 7, p. 765-774, Jan. 2003.

THOMAZ FILHO, A.; CESERO, P.; MIZUSAKI, A. M.; LEÃO, J. G. Hot spot volcanic tracks and their implications for south american plate motion, Campos basin (Rio de Janeiro state), Brazil. Journal of South American Earth Sciences, v. 18, n. 3-4, p. 383-389. 2005.

TURCOTTE, D.L.; SCHUBERT, G. Geodynamics: Applications of Continuum Physics to Geological Problems. John Wiley and Sons, New York, first edition, 450 pags, 1982.
ULBRICH H.H. \& ULBRICH M.N.C. O Maciço Alcalino de Poços de Caldas, MG - SP: características petrográficas e estruturais. In: SBG/ Congresso Brasileiro de Geologia, 37, São Paulo, Roteiro de Excursões. 64 págs. 1992.

ULBRICH, H.H.G.J.; VLACH, S.R.F.; ULBRICH; M.N.C.; KAWASHITA, K.). Penecontemporaneous syenitic-phonolitic and basic-ultrabasic-carbonatitic rocks at the Poços de Caldas alkaline massif, SE Brazil: geologic and geochronologic evidence. Revista Brasileira de Geociencias., Geoc., 32(1): 15-26. 2002.

WAGNER, G.A., \& VAN DEN HAUTE, P. Fission TrackDating. Kluwer Academic Publishers, Dordrecht, 285 pp. 1992.

ZALAN, P. V., \& OLIVEIRA, J. B. A.. Origem e Evolução Estrutural do Sistema de Riftes Cenozóicos do Sudeste do Brasil. Geociências. Petrobras, Rio De Janeiro, V. 13, N. 2, P. 269-300. 2005. 